\title{
Intuitionistic Neuro-Fuzzy Optimization in the Management of Medical Diagnosis
}

\author{
Nivedita1, Seema Agrawal'1, Dhanpal Singh'2, Mukesh Kumar Sharma3 ${ }^{3}$ \\ ${ }^{1}$ Department of Mathematics, S. S. V. (P. G.) College, Hapur, India \\ ${ }^{2}$ Department of Mathematics, Keshav Mahavidyalaya, University of Delhi, New Delhi, India \\ ${ }^{3}$ Department of Mathematics, Chaudhary Charan Singh University, Meerut, India \\ Email: niveditasingh.rs@gmail.com, seemagrw17@gmail.com,drdhanpalsingh@gmail.com,drmukeshsharma@gmail.com
}

How to cite this paper: Nivedita, Agrawal, S., Singh, D. and Sharma, M.K. (2021) Intuitionistic Neuro-Fuzzy Optimization in the Management of Medical Diagnosis. Applied Mathematics, 12, 993-1020. https://doi.org/10.4236/am.2021.1211065

Received: September 28, 2021

Accepted: November 22, 2021

Published: November 25, 2021

Copyright (c) 2021 by author(s) and Scientific Research Publishing Inc. This work is licensed under the Creative Commons Attribution International License (CC BY 4.0).

http://creativecommons.org/licenses/by/4.0/

\section{(c) (i) Open Access}

\begin{abstract}
Diabetes has become a major concern nowadays and its complications are affecting various organs of a diabetic patient. Therefore, a multi-dimensional technique including all parameters is required to detect the cause, its proper diagnostic procedure and its prevention. In this present work, a technique has been introduced that seeks to build an implementation for the intelligence system based on neural networks. Moreover, it has been described that how the proposed technique can be used to determine the membership together with the non-membership functions in the intuitionistic environment. The dataset has been obtained from Pima Indians Diabetes Database (PIDD). In this work, a complete diagnostic procedure of diabetes has been introduced with seven layered structural frameworks of an Intuitionistic Neuro Sugeno Fuzzy System (INSFS). The first layer is the input, in which six factors have been taken as an input variable. Subsequently, a neural network framework has been developed by constructing IFN for all the six input variables, and then this input has been fuzzified by using triangular intuitionistic fuzzy numbers. In this work, we have introduced a novel optimization technique for the parameters involved in the INSFS. Moreover, an inference system has also been framed for the neural network known as INFS. The results have also been given in the form of tables, which describe each concluding factor.
\end{abstract}

\section{Keywords}

Intuitionistic Fuzzy Set, Neural Network, Neuro-Fuzzy System, Intuitionistic Neuro-Fuzzy System, Optimization, Medical Diagnosis

\section{Introduction}

Present day's diabetes becomes a major health problem causing many health is- 
sues in the human body. Delay in the initial identification of diabetes becomes crucial to control the severity of the disease. Many specific techniques of the prevention and diagnosis for diabetes based on fuzzy logic have already been done so far. Fuzzy logic was first introduced in 1965 by Zadeh [1]. The tremendous utility of fuzzy logic has been used in different fields of science, engineering and medicine. Kabiraj et al. gave the utility of fuzzy logic has been used in linear programming [2] [3]. Lee, C.S. and Wang, M.H. gave a fuzzy expert system application for the Ontology-based on intelligent healthcare "Global Neglected Tropical Disease (GNTD)" application to respiratory waveform recognition which gave better results from previous researches [4]. Olej, V. and Hájek, P. designed Inference systems aimed at the forecast of ozone for time series: the situation of Pardubice micro-region showed again in addition to their work, Inference systems with Takagi-Sugeno type in ozone prediction by using comparison of fuzzy operators [5]. Olej and Hájek [6] compared the fuzzy operators Takagi-Sugeno Inference system in ozone prediction. Kalpana, M. and Dr. Kumar, A.V.S. also proposed a system which was the fuzzy expert system with the help of a fuzzy verdict machine for fuzzy rules by fuzzifying the input factors into triangular intuitionistic fuzzy numbers. The whole process is the diagnosis of diabetes. This system gave much accurate results in diagnosing diabetes in comparison to all previous studies [7]. Habib, S. and Akram, M. designed a decision-making system for washing machines by using AIFNN which is very useful nowadays [8]. Jain, V. and Raheja, S. suggested another fuzzy expert system for improving the prediction rate of diabetes their system gave better results from the system which was designed by Kalpana, M. and Dr. Kumar, A.V.S. [9]. Ahmadi, H. proposed a method for diseases diagnosis by using fuzzy logic methods, which is a systematic and meta-analysis review [10]. Bressan, G. M. also suggested a system for diabetes mellitus type-2 classifications which was based on a fuzzy approach [11]. But, due to the consideration of membership grade only, fuzzy logic failed to handle the uncertainty, presents in the diagnosis process. So, we need compellable tools that can deal with that kind of situation. In the last few decades, many efforts have been done to bring out a common framework of neural networks and fuzzy expert systems. First, Detlef Nauck and Rudolf Kruse gave a neuro-fuzzy technique for the classification of data named NEFCLASS which was presented in the symposium proceeding on applied computing [12]. Musilek, P. and Gupta, M. gave the theory of fuzzy systems which provides a mathematical framework for capturing the uncertainties with human cognitive processes [13]. Goncalves, L.B. et al. designed such a neuro-fuzzy system for the classification of pattern and rule mining for diabetes which was upturned into a classified neuro-fuzzy BSP system [14]. A seminal review has been provided by Jabbar and Mehrotra [15] in the context of ANN to decision-making in health care. Later on, for nonlinear systems, an ambiguous rule-based fuzzy neural system [16] with a constant knowledge mechanism has been studied [17]. Sentimentality in yearly reports was recognized for economic presentation. The study was given for the 
observation of outcomes of the sentiments on upcoming economic crisis [18]. A survey was given by Viharos and Kis on NFS in 2015 [19], this study also shows the utility of both the system, i.e., fuzzy inference system and neural network. [20] gave a prediction fuzzy model for identification and prevention of diabetes, this study expected the five major complications which have arisen due to diabetes. An adaptive neuro-fuzzy inference system [21] has also been studied to determine the economic order quantity and order implementation. Atanassov [22] [23] presented the concept of the intuitionistic fuzzy set that can handle uncertainty very well as compared to traditional fuzzy logic. In the study of intuitionistic fuzzy logic, we consider the values with two types of grades are as the membership and the other is non-membership. So, these methods give us a wide range to cover the uncertainness and vagueness. Neuro-fuzzy system has a vital role in the medical field, especially in the diagnostic process. A large amount of neuro-fuzzy systems has been studied over intuitionistic fuzzy sets. Intuitionistic fuzzy logic has also been used in many medical diagnosis tools. Sang and Zhang gave an approach which was based on Intuitionistic Fuzzy Information [24]. Barrenechea, E. et al. generalized the work of Atanassov's intuitionistic fuzzy index construction method [25], Hájek, P. and Olej, V. solved the regression problems by using an adaptive intuitionistic fuzzy inference system of Takagi-Sugeno type approach, afterwards they used again Takagi-Sugeno type intuitionistic Fuzzy Inference System (FIS) by using defuzzification methods to solve the matter of incorporated liquidation forecast, followed by these two works they added Intuitionistic Fuzzy Neural Network, a new approach in their work and got results for the situation of credit scoring using text acquaintance [26] [27] [28]. After Hájek, P. and Olej, V., Zhao, J. et al. proposed "a general fuzzy cerebella model neural network multidimensional classifier using Intuitionistic fuzzy sets for medical identification" [29]. Eyoh, I. et al. also introduced an intuitionistic fuzzy logic for regression problems that was of interval Type-2 fuzzy sets [30]. An advanced distance measurement technique on intuitionistic fuzzy set-in decision making was also studied [31]. Samuel, A.E. and Rajakumar, S. introduced the intuitionistic fuzzy sets that are useful in the field of medical diagnosis [32]. Chao, L. et al. gave such a network which helps in online learning and time series forecast named as an evolving recurrent interval type- 2 intuitionistic fuzzy neural network for online learning and time series forecast [33]. Shie-Jue, Lee and Chen-Sen, Ouyang [34] proposed a neuro-fuzzy system model that includes the input-output data found in two phases, in the primarily phase, the input-output datum gives the similarity and then by using the similarity a fuzzy network is constructed in the second step [35]. A genetic algorithm has also been used in the situation of SelfOrganized Fuzzy Neural Networks [36], optimized weight technique of artificial neural networks [37], the type-2 fuzzy logic system which is used for the linguistic prognostic models (for economic praxis) [38] and Elman model based neural network algorithm [39]. Later, a multidisciplinary technique has also been applied to artificial swarm intelligence to deal with heterogeneous computing and 
cloud scheduling [40]. In order to carry out the applications of fuzzy logic in the medical field, Guzman [41] proposed an optimized fuzzy qualifier for blood pressure disease. Tyagi, K. and Tyagi, K. published a paper A Comparative Analysis of Optimization Techniques, in which they used various techniques for the test cases of optimization to choose less vague test cases [42]. Later on, Parouha, R.P. and Verma, P. [43] also discussed various optimization techniques in the paper State-ofthe-Art Reviews of Meta-Heuristic Algorithms with Their Novel Proposal for Unconstrained Optimization and Applications. This paper is not only about GA and PSO but the comparison amongst different types of algorithms also done such that Meta-heuristic, aroused from the actions of societal creatures or animals, aroused from ecology, aroused by the laws leading a natural phenomenon, aroused from the human being.

The basic objectives of this research paper are pointed out the following points to focus the whole work as follows:

1) We will design a novel intuitionistic fuzzy logic based neural network approach for the diagnosis of diabetes.

2) We observed six input factors and with the help of the fuzzification process; we constructed the membership function for these inputs and with the help of Sugeno's fuzzy inference system. We applied this over the intuitionistic fuzzy numbers.

3) A new approach is developed for optimization to get the optimized weights of the neurons.

The present work is separated into nine sections. In Section 2, we defined some basic definitions related to intuitionistic fuzzy sets. In Section 3, a survey on optimization techniques is discussed. We proposed the intuitionistic neuro-fuzzy system in the form of Sugeno's intuitionistic neuro-fuzzy approach in Section 4 of the paper. In Section 5, the mathematical formulation and description of the system are given. The proposed optimization technique is also been described in Section 6 of the paper. In Section 7, the data collection method is given and Section 8 of the research paper describes the numerical computation part of the present work and comparison with the previous algorithm. In Section 9, the last section describes the discussions and conclusions of the paper.

\section{Basic Perceptions}

\subsection{Intuitionistic Fuzzy Set}

Let $S$ be any Intuitionistic fuzzy set on a universe of discourse $U$ is defined as:

$$
S=\left\{\left(\tau, \mu_{S}(\tau), v_{S}(\tau)\right): \tau \in U\right\}
$$

where $\mu_{S}(\tau) \in[0,1]$ is called the "degree of membership" of $\tau$ in $S$ and $v_{S}(\tau) \in[0,1]$ is called the "degree of non-membership" of $\tau$ in $S$. Where, $0 \leq \mu_{S}(\tau)+v_{S}(\tau) \leq 1$. Here, $\pi_{S}(\tau)=1-\left[\mu_{S}(\tau)+v_{S}(\tau)\right]$ is called hesitational 
part of $\tau . \pi_{S}(\tau)$ can also be considered as the degree for the lack of uncertainty related with the membership or non-membership grades in $S$.

The membership and non-membership functions for the trapezoidal and triangular intuitionistic fuzzy number in real line $\mathrm{R}$, is defined by:

For Trapezoidal:

$$
\begin{gathered}
\mu_{S}(\tau)= \begin{cases}\frac{\tau-a}{b-a}, & a \leq \tau \leq b \\
1, & b \leq \tau \leq c \\
\frac{d-\tau}{d-c}, & c \leq \tau \leq d \\
0, & \text { else }\end{cases} \\
v_{S}(\tau)= \begin{cases}\frac{a^{*}-\tau}{b-a^{*}}, & a^{*} \leq \tau \leq b \\
0, & b \leq \tau \leq c \\
\frac{\tau-d^{*}}{d^{*}-c}, & c \leq \tau \leq d^{*} \\
1, & \text { else }\end{cases}
\end{gathered}
$$

with $a^{*}<a<b<c<d<d^{*}$.

For Triangular:

$$
\begin{aligned}
& \mu_{S}(\tau)= \begin{cases}\frac{\tau-a}{b-a}, & a \leq \tau \leq b \\
\frac{c-\tau}{c-b}, & b \leq \tau \leq c \\
0, & \text { else }\end{cases} \\
& v_{S}(\tau)= \begin{cases}\frac{a^{*}-\tau}{b-a^{*}}, & a^{*} \leq \tau \leq b \\
\frac{\tau-c^{*}}{c^{*}-b}, & b \leq \tau \leq c^{*} \\
1, & \text { else }\end{cases}
\end{aligned}
$$

with $a^{*}<a<b<c<c^{*}$.

\subsection{Neural Network}

A neural network is a network of neurons that is combination of nodes and links. An artificial neuron constructs a "Artificial Neural Network (ANN)" or "Artificial Neural Systems" and behave like the intelligence of human beings. Neural Network is a natural biological process used for solving the Artificial Intelligence (AI) models. In this structure, we have used the network neurons with the weights function. They have information about the inputs. In this we have constructed the activation function to get the rule in the form of linear combination of inputs and give the extension for the output.

For example, usually the range of output is between $o$ and 1 but it could be -1 and 1. 


\subsection{Neural Fuzzy System}

A neuro-fuzzy system is a learning mechanism which finds the constraints of a fuzzy system by manipulating the estimate systems from neural networks. The Fuzzy Neuro System is a construction of FNN (N, W, P, Q, A) with following conditions:

1) $\mathrm{N}$ is a non-empty set of fuzzy neurons and supplementary units.

2) By the given model and constraints of the fuzzy neuro system are defined as the weight matrix $\mathrm{W}$ given by Cartesian product $\mathrm{N} \times \mathrm{N} \rightarrow \mathrm{DW}$ ( $\mathrm{DW}$ is the domain of weights).

3) Fuzzy inputs' vector $P \in D P$ defines the inputs of the fuzzy neuro system (DP is defined as the domain of the input vector).

4) Fuzzy outputs' vector $Q \in D Q$ defines the output for the fuzzy neuro system (DQ is defined as the domain of the output vector).

5) The learning algorithm A defines the phases of learning and adaptation for the new data (usually by changing the weights matrix W).

\subsection{Optimization}

An optimization problem comprises of maximizing or minimizing an actual function by methodically selecting input values from inside an allowable set and computation for the values of the function. Main aim of optimization is to maximize or minimize the values for better result. The simplification of optimization concept and methods to other formulations create a huge area of applied mathematics. Specifically, optimization contains searching "best available" values for some objective function specified a well-defined input, with a variety of objective functions and various types of inputs.

The methods presently accessible in works for resolving optimization difficulties may generally be classified as deterministic methods and probabilistic methods. Nature inspired algorithms are most popular population-based algorithms mimicking the evolutionary, self-organizing and collective process of nature. Some nature-inspired algorithms use the concepts of natural evolutions like selection, reproduction, crossover and mutation; some display the socio-cooperative behavior of natural species like birds, ants, termites, bees and humans well These algorithms are termed as metaheuristic algorithms such as Genetic Algorithms, Particle Swarm Optimization, Ant Colony Optimization, Differential Evolution, SelfOrganizing Migrating Algorithm and many more.

\section{Related Background}

A survey has been done over the evolution of various kinds of algorithms for the presented research work. These algorithms are inspired from natural phenomenon and their social behaviors which helps in finding the optimized values for any given problem [43]-[71].

The survey of this study has been listed in the given Table 1, which is as follows: 
Table 1. Evolution of different algorithms.

\begin{tabular}{|c|c|c|c|}
\hline $\begin{array}{l}\text { Reference } \\
\quad \text { No. }\end{array}$ & Author's Name & Name of Technique & Problem Controlled \\
\hline$[44]$ & $\begin{array}{l}\text { Fonseca, C.M. and } \\
\text { Fleming, P.J. [1993] }\end{array}$ & $\begin{array}{l}\text { (MOGA) Multi-Objective } \\
\text { Genetic Algorithm }\end{array}$ & Optimization \\
\hline$[45]$ & Horn, J. et al. [1994] & $\begin{array}{l}\text { (NPGA) Niched Pareto } \\
\text { Genetic Algorithm }\end{array}$ & $\begin{array}{l}\text { Multi-Objective } \\
\text { Optimization }\end{array}$ \\
\hline [46] & Srinivas, N. and Deb, K. [1995] & $\begin{array}{l}\text { (NSGA) Non-Dominated } \\
\text { Sorting Genetic Algorithms }\end{array}$ & $\begin{array}{l}\text { Multi-Objective } \\
\text { Optimization }\end{array}$ \\
\hline [47] & Stutzle, T. [1998] & (PAS) Parallelization of Ant System & $\begin{array}{l}\text { Combinatorial } \\
\text { Optimization }\end{array}$ \\
\hline [48] & $\begin{array}{l}\text { Bullnheimer, B., Hartl, R.F. } \\
\text { and Strauss, C. [1997] }\end{array}$ & (AS rank) Rank Based Ant System & TSP \\
\hline$[49]$ & $\begin{array}{l}\text { Van den Bergh, F. and Engelbrecht, A. } \\
{[2002]}\end{array}$ & $\begin{array}{l}\text { (GCPSO) Guaranteed Convergence } \\
\text { Particle Swarm Optimization }\end{array}$ & $\begin{array}{l}\text { Convergence to } \\
\text { Local Minimum }\end{array}$ \\
\hline$[50]$ & $\begin{array}{l}\text { Yang, C. and } \\
\text { Simon, D. [2005] }\end{array}$ & $\begin{array}{l}\text { (HPSO) Hierarchical Particle } \\
\text { Swarm Optimization }\end{array}$ & Better Solution \\
\hline [51] & Janson, S. and Middenfort, M. [2006] & $\begin{array}{l}\text { (NPSO) New Particle } \\
\text { Swarm Optimization }\end{array}$ & Better Solution \\
\hline$[52]$ & $\begin{array}{l}\text { Kim, D.H. et al. } \\
\text { [2007] }\end{array}$ & (HGA) Hybrid Genetic Algorithm & Global Optimization \\
\hline [53] & $\begin{array}{l}\text { Hu, X.M., Zhung, J. and } \\
\text { Li, Y. [2008] }\end{array}$ & $\begin{array}{l}\text { (COAC) Continuous } \\
\text { Orthogonal Ant Colony }\end{array}$ & $\begin{array}{c}\text { Continuous } \\
\text { Optimizing Problems }\end{array}$ \\
\hline$[54]$ & $\begin{array}{l}\text { Yu, B., Yang, Z-Z. and } \\
\text { Yao, B.Z. [2009] }\end{array}$ & $\begin{array}{l}\text { (IACO) Improved Ant } \\
\text { Colony Optimization }\end{array}$ & Vehicle Routing \\
\hline [55] & $\begin{array}{c}\text { Ruhana, K. and } \\
\text { Aljanaby, K.M.A. [2010] }\end{array}$ & $\begin{array}{l}\text { (IMACO) Interacted Multiple } \\
\text { Ant Colony Optimization }\end{array}$ & Different Instances of TSP \\
\hline [56] & Taspnar, N. [2010] & $\begin{array}{l}\text { (ABC-PTS) Partial Transmit Sequences } \\
\text { (PTSs) Based on ABC }\end{array}$ & $\begin{array}{l}\text { Peak-to-Average } \\
\text { Power Ratio }\end{array}$ \\
\hline [57] & El-Abd, M. [2011] & $\begin{array}{c}\text { (OABC) ABC with the Concept of } \\
\text { Opposition Number-Based Optimization }\end{array}$ & Black Box Optimization \\
\hline [58] & Sonmez, M. [2011] & $\begin{array}{l}\text { (ABC-AP) Artificial Bee Colony with } \\
\text { Adaptive Penalty Function }\end{array}$ & Weight of Truss Structures \\
\hline [59] & Gupta, D.K., Arora, Y. et al. [2012] & $\begin{array}{l}\text { (RMACO) Recursive Multiple } \\
\text { Ant Colony Optimization }\end{array}$ & $\begin{array}{c}\text { Estimation of } \\
\text { Parameters of a Function }\end{array}$ \\
\hline$[60]$ & Deepak, R. et al. [2014] & $\begin{array}{l}\text { (HBMO) Honeybee Mating } \\
\text { Optimization Algorithm }\end{array}$ & Test Case Optimization \\
\hline [61] & Tsai, P.W. et al. [2014] & $\begin{array}{l}\text { (IABC) Interactive Artificial } \\
\text { Bee Colony Optimization }\end{array}$ & Numerical Optimization \\
\hline$[62]$ & Zheng, Y.J. [2015] & (WWO) Water Wave Optimization & Train Scheduling Problem \\
\hline$[63]$ & Mirjalili, S. and Lewis, A. [2016] & (WOA) Whale Optimization Algorithm & Multimodal Functions \\
\hline
\end{tabular}


Continued

[64]

Xiong, H., Qiu, B. and Liu, J. [2020]

[72]

Saremi, S., Mirjalili, S.

Yu, H. et al. [2018]

Pierezan, J. and Dos Santos Coelho, L. [2018]

Khajeh, A., Ghasemi, M.R. and Arab, H.G. [2019]

Shabani, A. et al. [2019]

Hosseini, S.A., Hajipour, A. and Tavakoli, H. [2019]

Marzbali, A.G. [2020]

Dash, J., Dam, B. and Swain, R. [2020]
(GOA) Grasshopper

Optimization Algorithm

(SHPSO) Surrogate-Assisted Hierarchical PSO

(COA) Coyote Optimization Algorithm

(MPSO) Modified PSO with Novel

Population Initialization

(SAR) Search and Rescue Optimization

(HAFPSO) Hunter-Attack

Fractional-Order PSO

(BSSA) Bear Smell Search Algorithm

(NMSPSO) Novel Multi-Swam PSO

(HDEPSO) Hybrid Differential Evolution Particle Swarm Optimization
Real Life Problems

High-Dimensional

Problems

Global

Optimization Problems

Benchmark Function

Optimization

Single-Objective

Continuous

Optimization Problems

Optimum Design

of Power Amplifier

Real World

Engineering Problems

Real-World

Applications Problem

Sharp Edge FIR Filter

(SEFIRF) Design Problem

\section{Intuitionistic Neuro-Fuzzy System}

We introduced the structure of Intuitionistic Neuro Sugeno Fuzzy System (INSFS) for multilayered neural network. The detail of this network is as follows:

We consider if-then based rules of Sugeno's approach. Initially, we will construct a structure of six inputs with one output then inputs are further categorized into three or four linguistic terms and divided in Membership and NonMembership in the context of favorable and unfavorable cases. Our inputs are $I_{1}$, $I_{2}, I_{3}, I_{4}, I_{5}$ and $I_{6}$ and $y_{i}$ is the functional consequent value for each $i=1,2,3$, $4, \ldots$, where $I$ denotes the number of rules.

Let $\mathrm{i}^{\text {th }}$ if-then rule of INSFS expressed as:

IF $I_{1}$ is $X_{1}$ and $I_{2}$ is $X_{2}$ and $I_{3}$ is $x_{3}$ and $I_{4}$ is $X_{4}$ and $I_{5}$ is $x_{5}$ and $I_{6}$ is $X_{6}$.

Then $y_{i}$ can be stated as:

$$
y_{i}=\alpha_{i_{0}}+\alpha_{i_{0}} I_{1}+\alpha_{i_{1}} I_{2}+\cdots+\alpha_{i_{n}} I_{n}
$$

where $x$ denotes the linguistic characterization variables into three categories as; Low, Medium, Normal, High, Overweight \& Obesity class I, Obesity class II \& III, Less High, More High, Most High, Less Chance, More Chance, Most Chance and High Risk (such that L, M, N, H, OW, OB, LH, MRH, MTH, LC, MRC, MTC and HR respectively). The linguistic characterization variables are further divided into two categories membership and non-membership shown in Figure 1. 


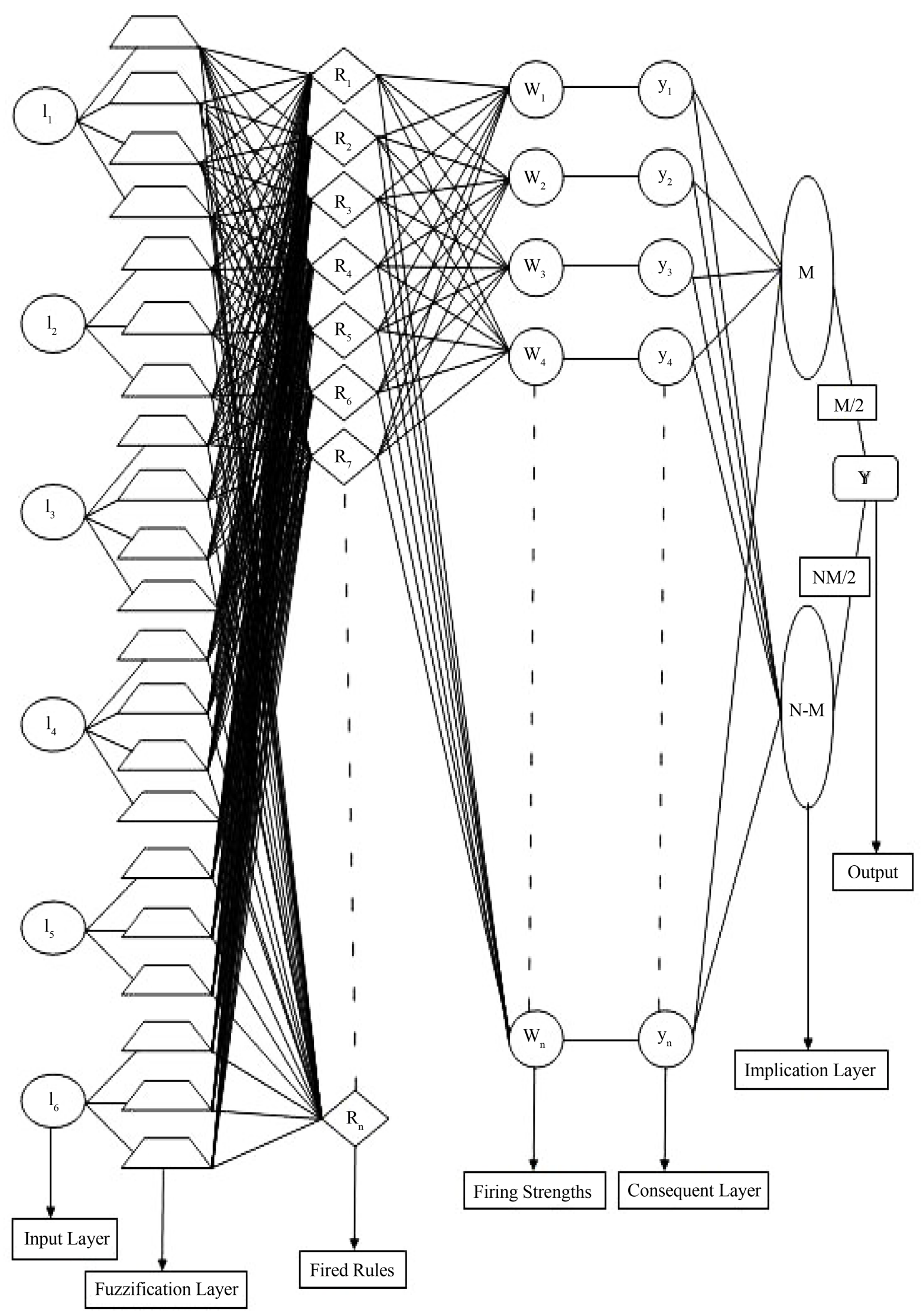

Figure 1. Proposed structure of INSFS. 


\section{Description of System and Mathematical Formulation}

Layer 1 (Input Layer): we define layer 1 as input layer in which we taken six inputs and use the non-linear system which is considered as combination of several linear systems or non-linear systems. The membership functions for this input layer have shown in Figure 2.

Layer 2 (Fuzzification): we described this layer as fuzzification layer. In these layers neurons receives an input which will fuzzify this layer with some degree of membership or non-membership. After the fuzzification this layer works as input for layer 3. This is simply the membership and non-membership values for the given inputs.

We have used Trapezoidal and Triangular function in our work, for example, Membership and Non-Membership function for Glucose:

For membership function:

$$
\begin{gathered}
\mu_{L}= \begin{cases}1, & 0 \leq x \leq 25 \\
\frac{50-x}{25}, & 25 \leq x \leq 50\end{cases} \\
\mu_{N}= \begin{cases}\frac{x-25}{25}, & 25 \leq x \leq 50 \\
1, & 50 \leq x \leq 95 \\
\frac{120-x}{25}, & 95 \leq x \leq 120\end{cases} \\
\mu_{M}= \begin{cases}\frac{x-95}{25}, & 95 \leq x \leq 120 \\
1, & 120 \leq x \leq 162 \\
\frac{180-x}{18}, & 162 \leq x \leq 180\end{cases} \\
\mu_{H}= \begin{cases}\frac{x-172}{18}, & 172 \leq x \leq 190 \\
1, & x \geq 190\end{cases}
\end{gathered}
$$

For non-membership function:

$$
\begin{gathered}
v_{L}= \begin{cases}\frac{x-25}{18}, & 25 \leq x \leq 50 \\
0, & x \leq 25\end{cases} \\
v_{N}= \begin{cases}\frac{50-x}{25}, & 25 \leq \tau \leq 50 \\
0, & 50 \leq \tau \leq 95 \\
\frac{x-95}{25}, & 95 \leq \tau \leq 120\end{cases} \\
v_{M}= \begin{cases}\frac{120-x}{25}, & 95 \leq \tau \leq 120 \\
0, & 120 \leq \tau \leq 162 \\
\frac{x-162}{18}, & 162 \leq \tau \leq 180\end{cases}
\end{gathered}
$$




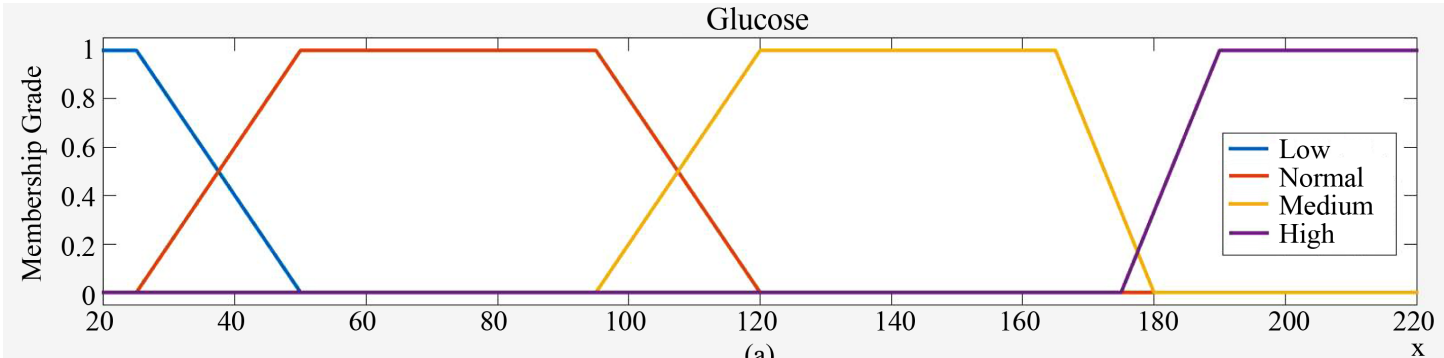

(a)

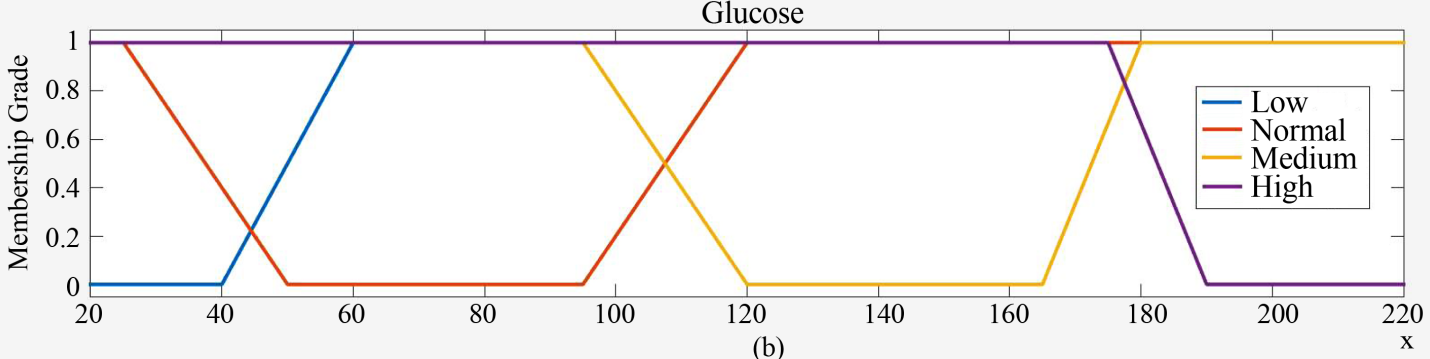

(b)

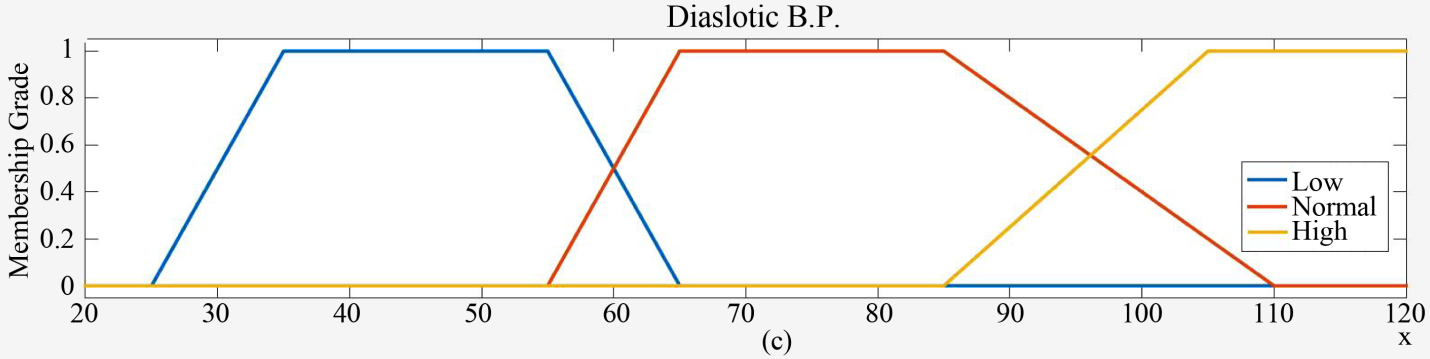

Diaslotic B.P

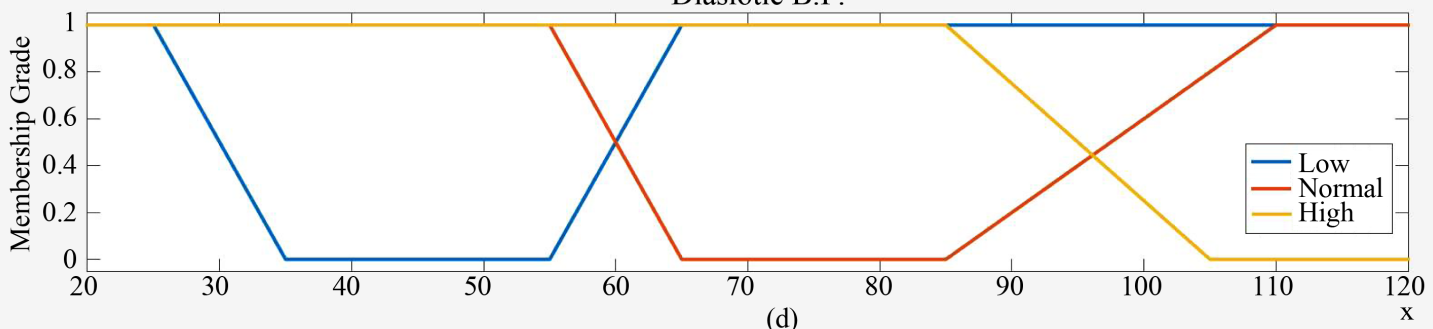

BMI

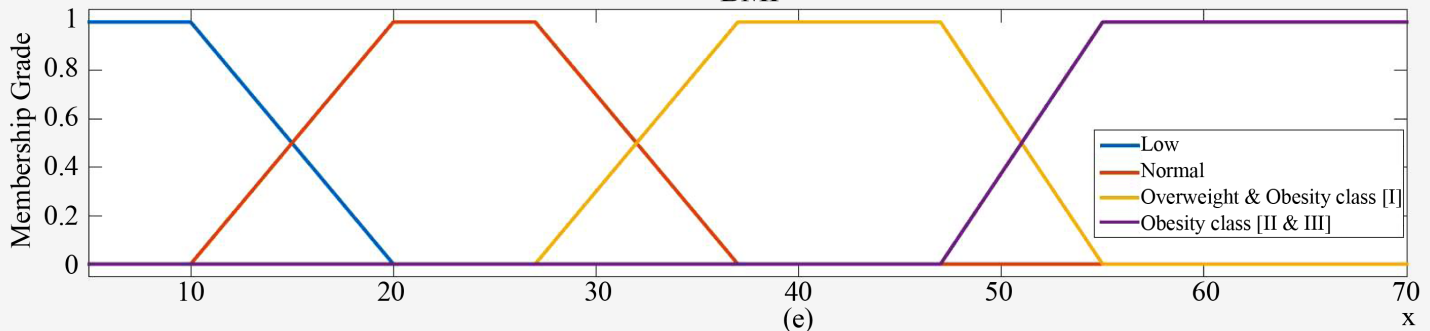

BMI

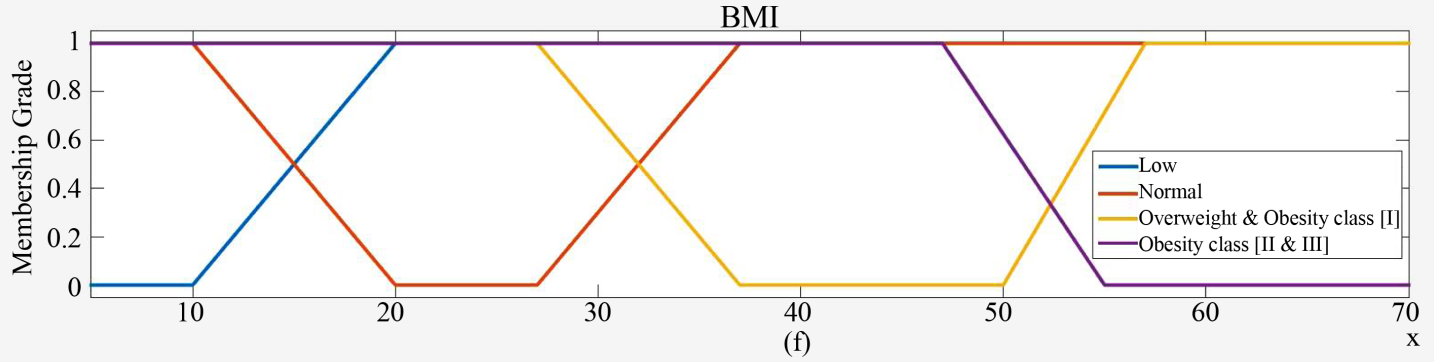



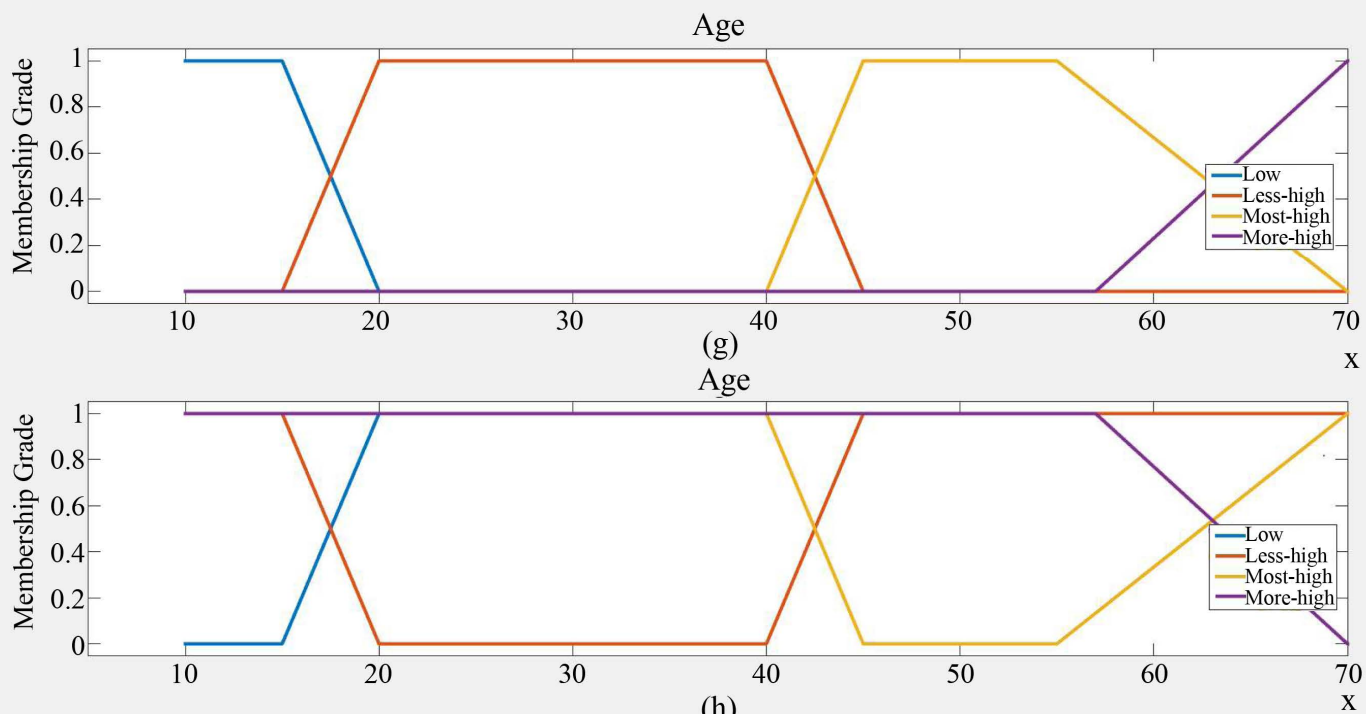

(h)

Diabetes Pedigree Function

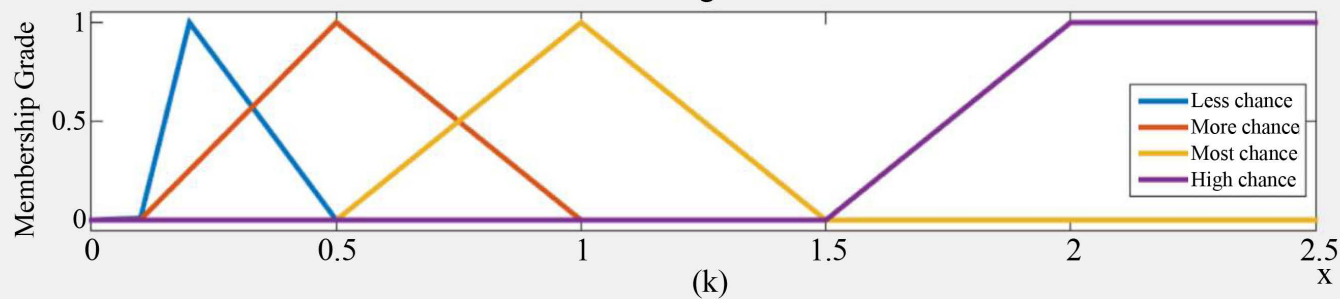

Diabetes Pedigree Function

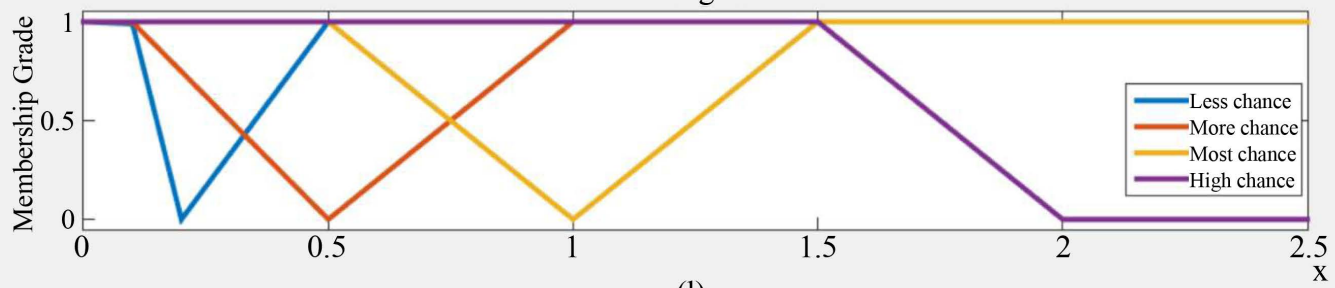

(1)
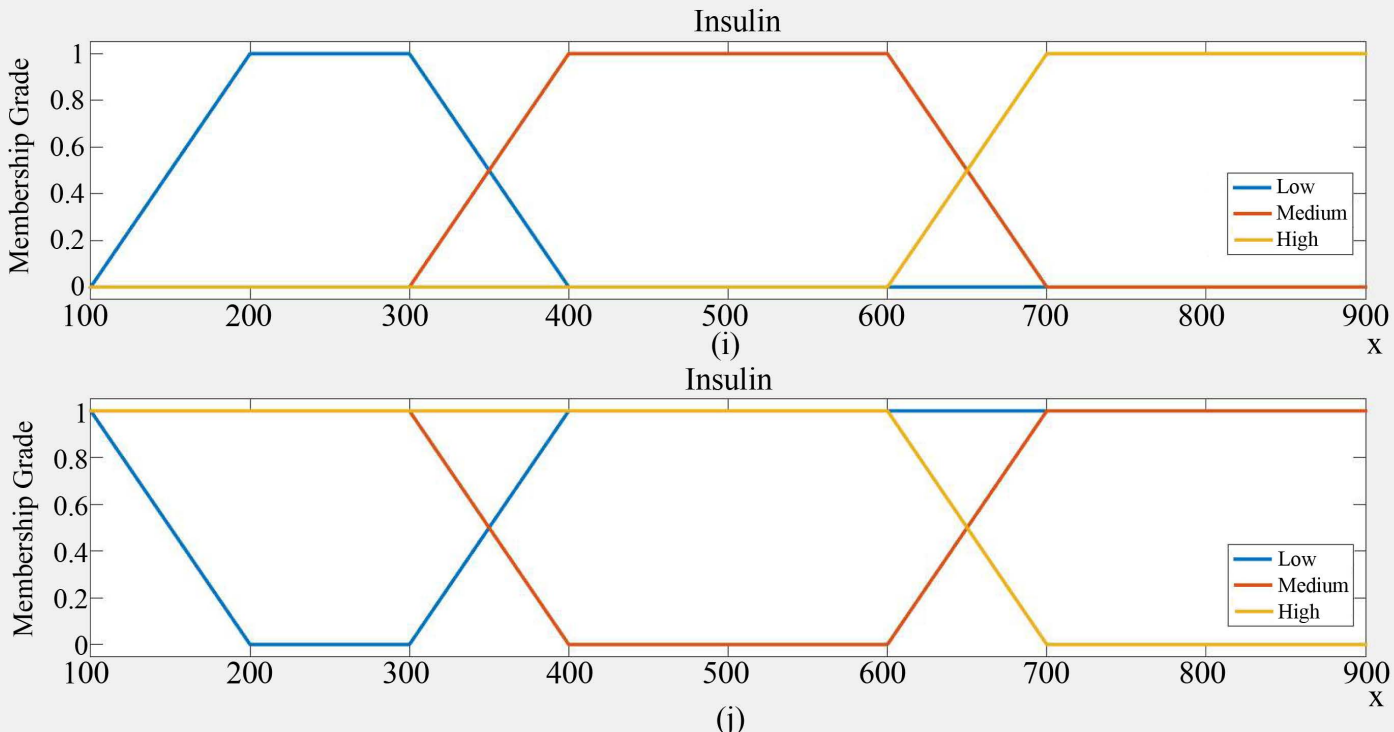

Figure 2. The graphical representation for the membership and non-membership grade of input factors. 


$$
v_{H}= \begin{cases}\frac{190-x}{18}, & 172 \leq x \leq 190 \\ 0, & 190 \leq x \leq 200\end{cases}
$$

Layer 3 (Fired set of Inputs): In this layer, we choose those rules which should be fired out of the total number of rules which are constructed by the inputs, which as follows:

e.g.: IF $I_{1}$ is $x_{1}$ and $I_{2}$ is $x_{2}$ AND $I_{3}$ is $x_{3}$ and $I_{4}$ is $x_{4}$ and $I_{5}$ is $x_{5}$ and $I_{6}$ is $x_{6}$.

Layer 4 (Layer of Firing Strengths or Weights): This layer corresponds to an if-then rules with each neuron of sugeno's type and computes the firing strength for every rule by using Max-Min operator.

$$
W_{i}=\min _{i=1,2,3, \cdots}\left[\mu_{x_{1}}\left(I_{1}\right), \mu_{x_{2}}\left(I_{2}\right), \cdots, \mu_{x_{n}}\left(I_{n}\right)\right]
$$

and:

$$
W_{i}=\max _{i=1,2,3, \cdots}\left[v_{x_{1}}\left(I_{1}\right), v_{x_{2}}\left(I_{2}\right), \cdots, v_{x_{n}}\left(I_{n}\right)\right]
$$

Layer 5 (Functional Consequent Values): In this layer, we find the values of $\left(y_{i}^{\prime} s\right)$ with the help of fired set of inputs. These values help us in next layer, which are as follows:

$$
y_{i}=\alpha_{i_{0}}+\alpha_{i_{0}} I_{1}+\alpha_{i_{1}} I_{2}+\cdots+\alpha_{i_{n}} I_{n}
$$

Layer 6 (Implication Layer): Sixth layer of our system is described in the form of implication, which expresses the consequent part of our Sugeno-based approach. The objective of this layer is to find the average of Membership grade $(M)$ and Non-Membership grade ( $N M)$ as follows:

$$
M=\frac{\sum_{i=1}^{k} W_{i} y_{i}}{\sum_{i=1}^{k} W_{i}}
$$

$W_{i}$ is the minimum of membership values, and:

$$
N M=\frac{\sum_{i=1}^{k} W_{i} y_{i}}{\sum_{i=1}^{k} W_{i}}
$$

$W_{i}$ is the maximum of non-membership values:

Layer 7 (Output or Defuzzification Layer): This is the final layer of our system and output for our proposed system will be calculated as:

$$
Y=\frac{M+N M}{2}
$$

Moreover, the error for our proposed system is calculated as:

$$
e=\frac{(Y-T)^{2}}{2}
$$

where $Y$ is the output value calculated by our system and $T$ is the targeted values value.

Our system might be wrong in calculating and finding the correct output due to uncertainties in data. So, we have to optimize these errors by optimizing the weights which are used by us in the equation of $y_{i}$, 


$$
y_{i}=\alpha_{i_{0}}+\alpha_{i_{0}} I_{1}+\alpha_{i_{1}} I_{2}+\cdots+\alpha_{i_{n}} I_{n}
$$

where $i=1,2,3, \cdots$

\section{Proposed Optimization Technique}

We have the output equation as:

$$
y_{1}=\alpha_{0}+\alpha_{M} G+\alpha_{N} B P+\alpha_{N} B M I+\alpha_{M T H} A+\alpha_{L} I+\alpha_{L C} D P F
$$

in which we got six weights as $\alpha_{0}, \alpha_{M}, \alpha_{N}, \alpha_{N}, \alpha_{M T H}, \alpha_{L}, \alpha_{L C}$ that are to be optimized to minimize the error. In this respective work we used the general concept of Hit and Trial method to optimize the weights. The given method is used to minimize the error in this paper which can increase its accuracy.

In this method we have used a technique in which we choose the optimized value for the $\alpha_{0}, \alpha_{M}, \alpha_{N}, \alpha_{N}, \alpha_{M T H}, \alpha_{L}, \alpha_{L C}$ by any existing method. In this technique we find the values for these weights once and after that we used these values thoroughly for each example. This proposed technique is better than other techniques due to its low complexity in calculations. In other techniques we must do more complex calculations to optimize weights again and again but, in this technique, we optimize these weights once and use in whole calculation. Flow chart for this proposed technique has shown in Figure 3.

\section{Data Collection Method}

In this paper, we have used the dataset from the website of Pima Indians Diabetes Database (PIDD). PIDD is a huge group which has the large number of datasets for diabetes globally. The National Institute of Diabetes and Digestive and Kidney Diseases (NIDDK) [37] have studied the Pima Indians. And the database of PIDD for this work is saved from the Internet

(http://archive.ics.uci.edu/ml/).

\section{Numerical Computations and Comparison with Existing Algorithms}

We choose the patients randomly from the given data to check the output of diabetes; first, we developed the INSFS structure considering fuzzy rules based on Sugeno's Approach.

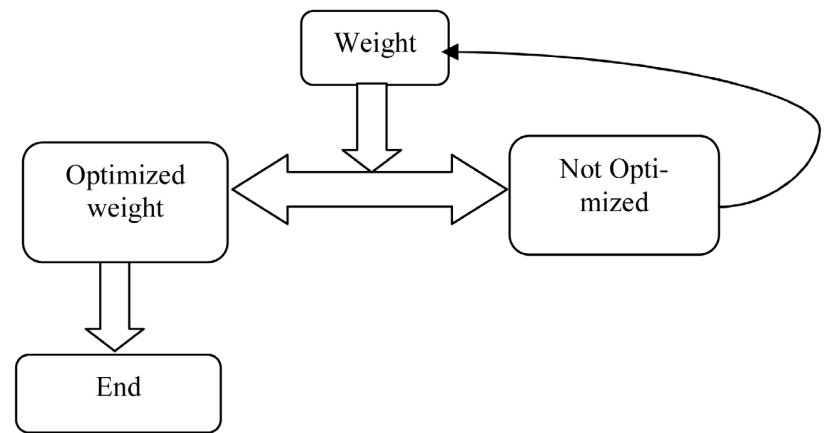

Figure 3. Representation of proposed technique. 
We have two outputs for diabetes i.e., 1 and 0 , which means Yes and No.

For example: we took one patient with ID 31which is shown in Table 2.

Layer 1: $G=145 \mathrm{mg} / \mathrm{dL} ; B P=82 \mathrm{mmHg} ; B M I=22.2 \mathrm{~kg} / \mathrm{m}^{2} ; A=57 \mathrm{yrs} ; I=$ $110 \mathrm{IU} / \mathrm{mL} ; D P F=0.245$ are six inputs for patient 31 .

Layer 2: After taken the values of inputs from given data we have to fuzzify them for further calculation.

So, the membership and non-membership values for given inputs given as:

For glucose: $\mu_{M}=1 \& v_{M}=0$;

For BP: $\mu_{N}=1 \& v_{N}=0$;

For insulin: $\mu_{L}=1 \& v_{L}=0$;

For BM: $\mu_{N}=1 \& v_{N}=0$;

For DPF: $\mu_{L C}=0.6375 \& v_{L C}=0.3625$;

For MRC: $\mu_{M R C}=0.49 \& v_{M R C}=0.51$;

For age: $\mu_{\text {MTH }}=1 \& v_{M T H}=0$.

Here we got two values for DPF as 0.245 lies between two ranges i.e., MRC and LC, which has given above.

Layer 3: Corresponding to these six inputs from all possible rules, we have only two rules, which will be fired in this case.

Therefore, we have two fired rules as follows:

$R_{1}$ : IF Glucose is medium and Diastolic B.P. is normal and BMI is normal and Age is most high and Insulin is low and DPF is less chance THEN output is:

$$
y_{1}=\alpha_{0}+\alpha_{M} G+\alpha_{N} B P+\alpha_{N} B M I+\alpha_{M T H} A+\alpha_{L} I+\alpha_{L C} D P F
$$

$\mathbf{R}_{2}$ : IF Glucose is medium and Diastolic B.P. is normal and BMI is normal and Age is most high and Insulin is low and DPF is more chance THEN output is:

$$
y_{1}=\alpha_{0}+\alpha_{M} G+\alpha_{N} B P+\alpha_{N} B M I+\alpha_{M T H} A+\alpha_{L} I+\alpha_{L C} D P F
$$

Layer 4: Weight or strength of the rules can be determined as follows:

$W_{1}$ :

$$
\min \left[\mu_{M}(145), \mu_{n}(82), \mu_{N}(22.2), \mu_{M T H}(57), \mu_{L}(110), \mu_{L C}(0.245)\right]
$$

and:

$$
\max \left[v_{M}(145), v_{n}(82), v_{N}(22.2), v_{M T H}(57), v_{L}(110), v_{L C}(0.245)\right]
$$

$W_{2}$ :

$$
\min \left[\mu_{M}(145), \mu_{n}(82), \mu_{N}(22.2), \mu_{M T H}(57), \mu_{L}(110), \mu_{L C}(0.245)\right]
$$

and:

$$
\max \left[v_{M}(145), v_{n}(82), v_{N}(22.2), v_{M T H}(57), v_{L}(110), v_{L C}(0.245)\right]
$$

i.e., $W_{1}=0.6375$ and 0.3625

$W_{2}=0.49$ and 0.51 .

Layer 5: We have calculated the values of functional consequent by the expression of $y_{i}$, which is the consequent part of fuzzy rules. After calculating, we have the values of $y_{1}$ and $y_{2}$ as follows: 
Table 2. Computational results for output, error and accuracy.

\begin{tabular}{|c|c|c|c|c|c|c|c|c|}
\hline 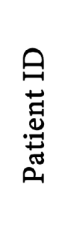 & 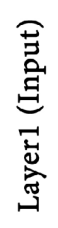 & 岕 & 岕 & 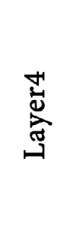 & 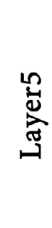 & $\begin{array}{l}\text { ర్ } \\
\text { త్ }\end{array}$ & 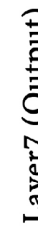 & 苛 \\
\hline
\end{tabular}
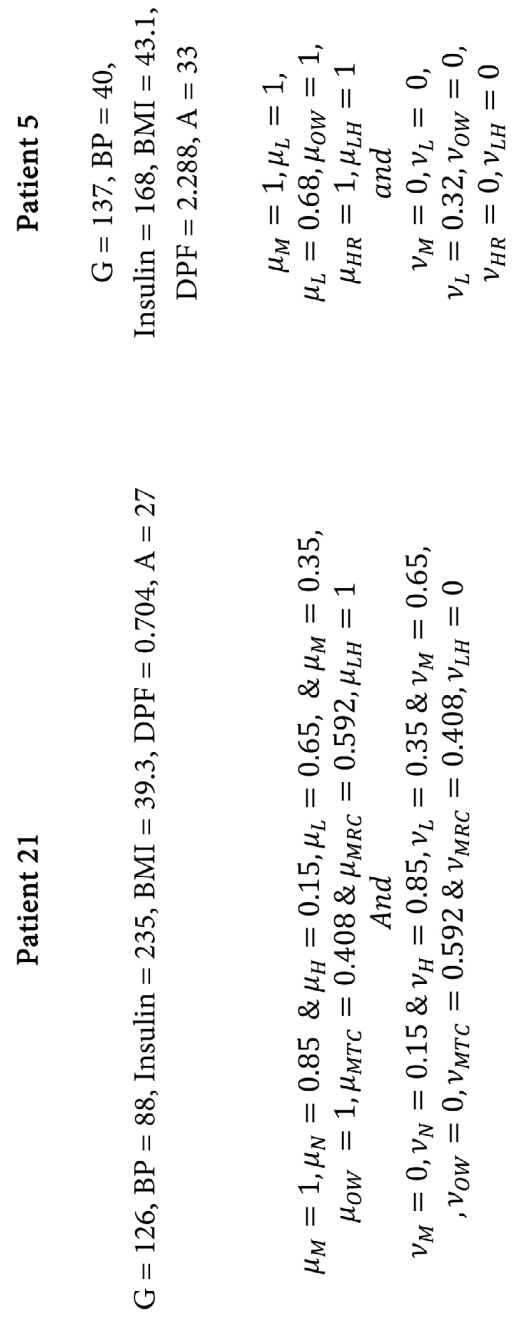

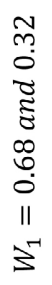

$\varangle \nabla \nabla \nabla \nabla \nabla \nabla \nabla$ $\times \times \times \times \times \times \times$

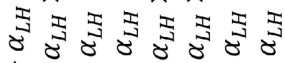
$++++++++$

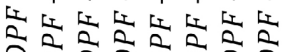

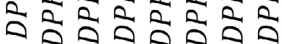
$\times \times \times \times \times \times \times$

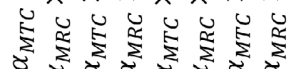

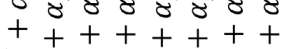
$\bar{z} \bar{\Sigma} \bar{z} \bar{z}$ $\sum_{\infty} \sum_{\infty} \sum_{\infty} \sum_{\infty} \sum_{\infty} \sum_{\infty} \sum_{\infty}$ 言 合 $++t+++++$ $\bar{x} \frac{\bar{x}}{\bar{x}} \bar{x} \frac{+}{x} \bar{x}$

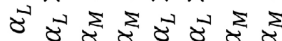
$+++++++$

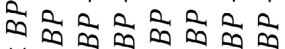
$\times \times \times \times \times \times \times$

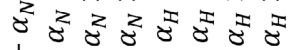

$+++++++$ u心u心u心 $\times \times \times \times \times \times \times$

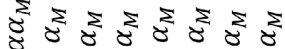
$+++++++$

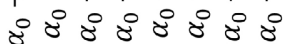
|| || || || || || || ||

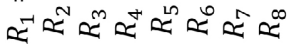

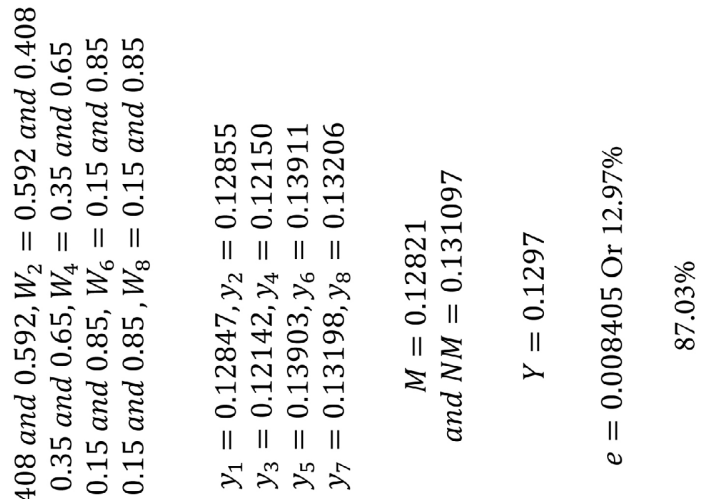

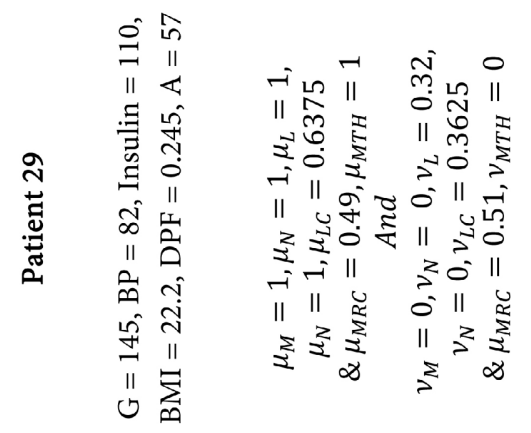

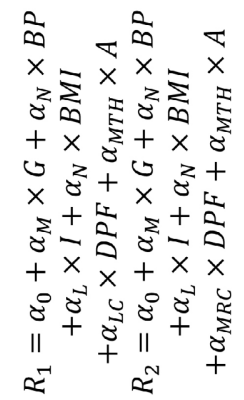

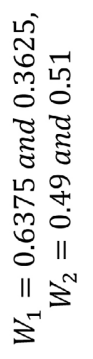

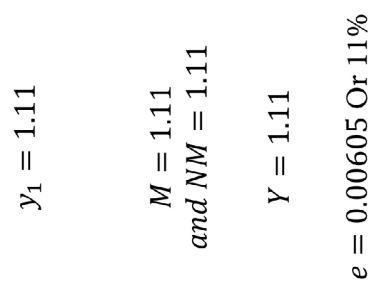

ণั || || ||

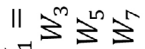




\section{Continued}

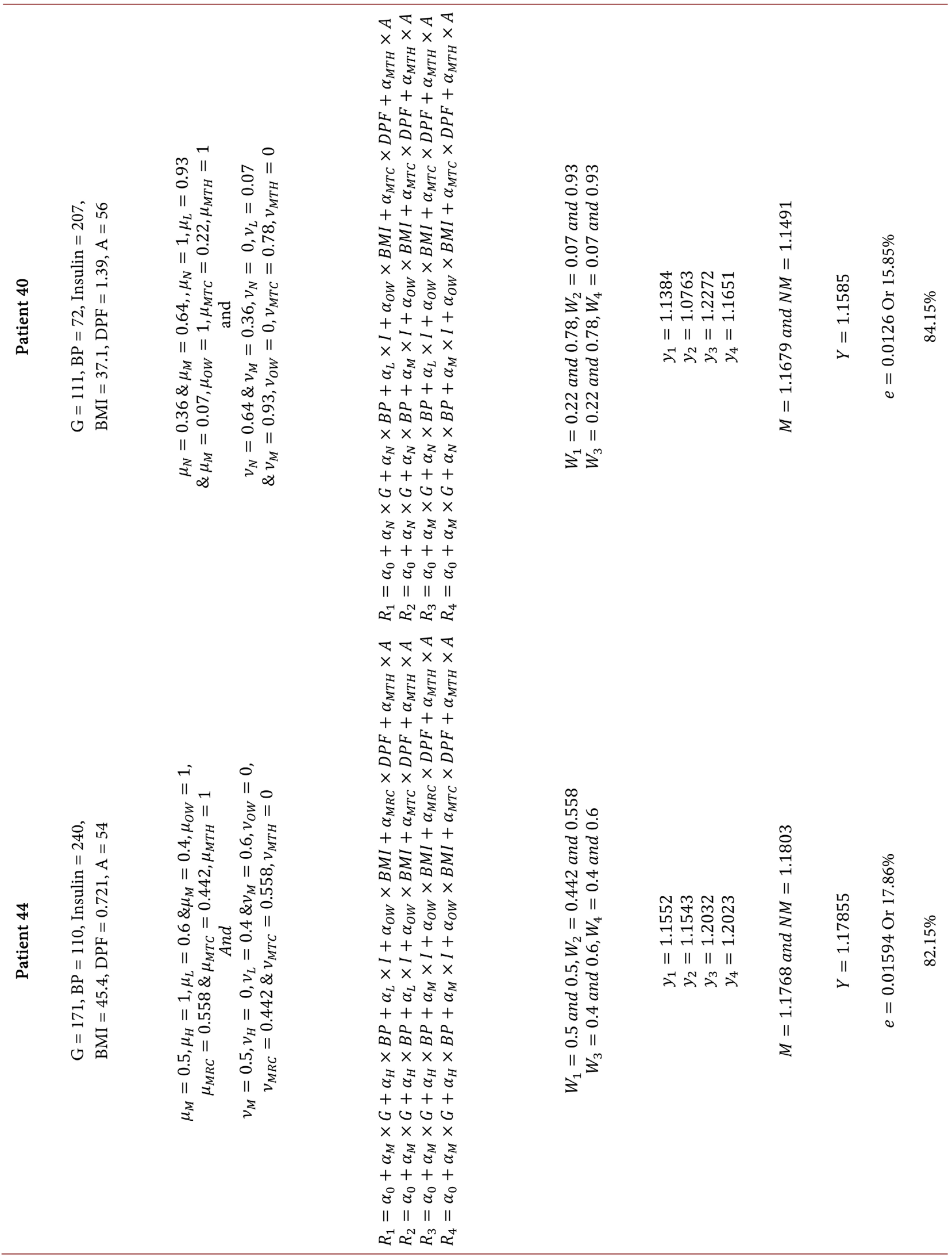




\section{Continued}

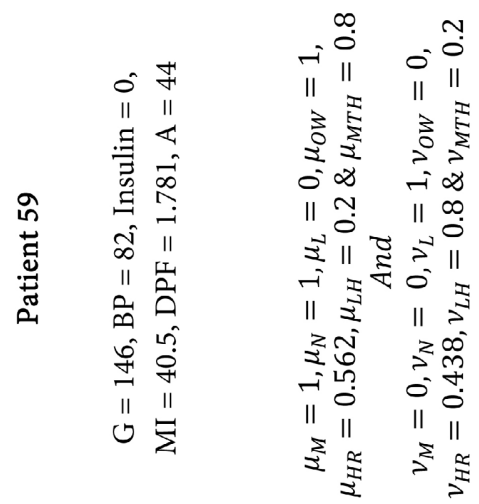

II

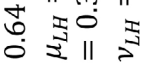

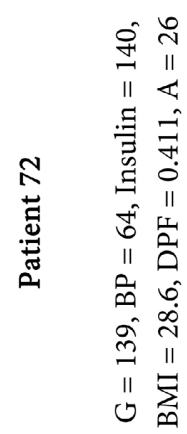

II $i$

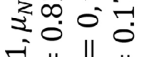

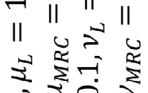

बाँ

$\|$ 约占

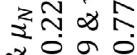

ఖ

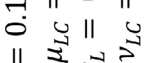

$11 \frac{2}{2} 5$

일

II $11 \sum \|$

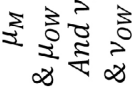

$\nabla \times \times \times \nabla \nabla \nabla \times$

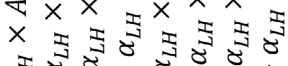

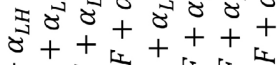

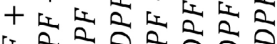

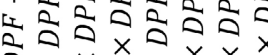

$\therefore \times \times \times x \times x$

$x$ u

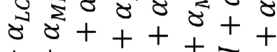

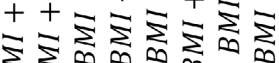

更 $\times \times \times \times \times$

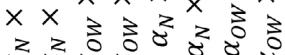

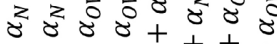
$++++\frac{+}{+} \pm$ $\bar{x} \overline{\times} \bar{x} \times \bar{x} \bar{x} \bar{x}$

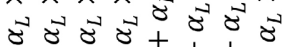
$++++0+++$ a a a $\frac{a}{\infty} \frac{a}{\infty}$ $\times \times \times \times \times \times \times$

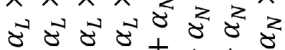
$+++++$ ৩心u心 $心 u v$

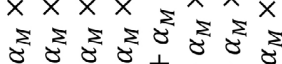
$+++++t+$

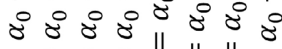
|| || || || || || ||

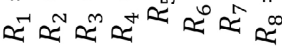

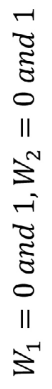
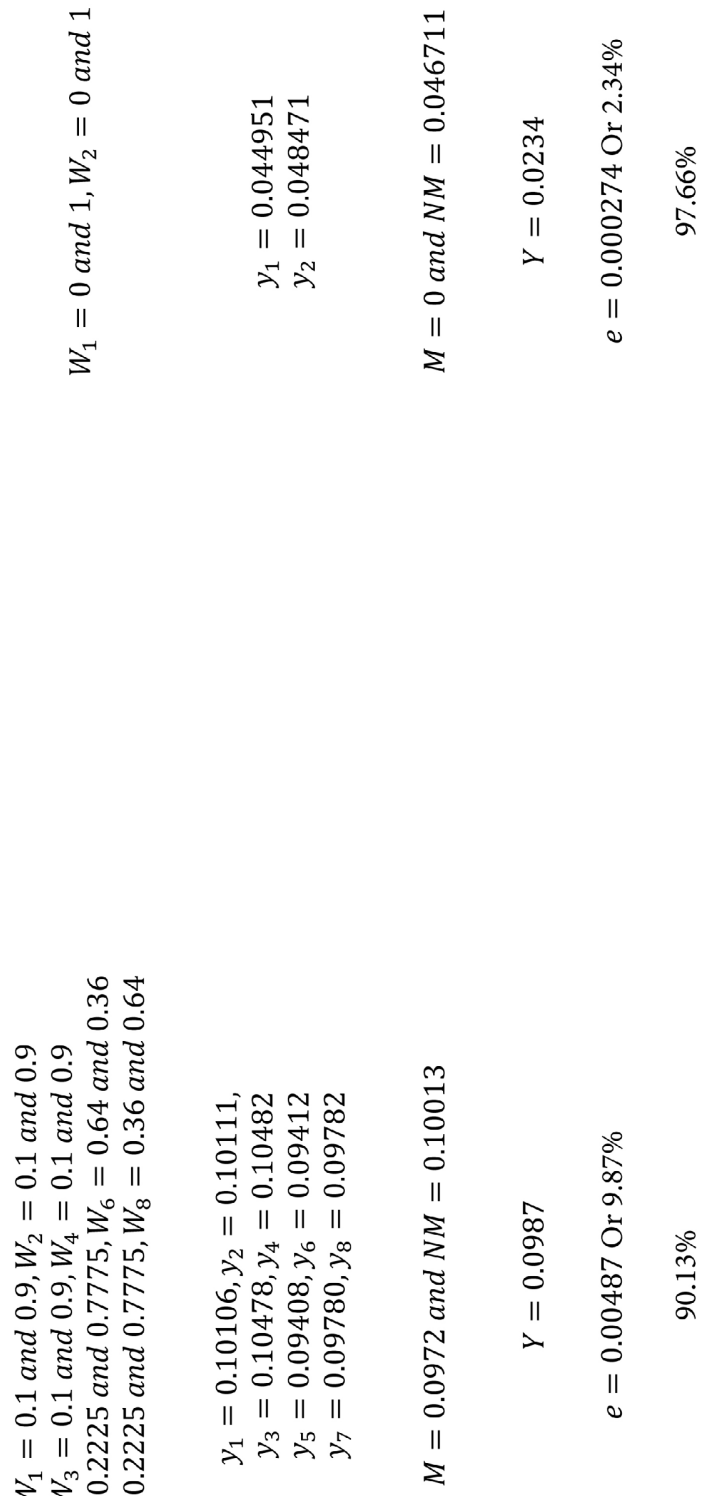


\section{Continued}

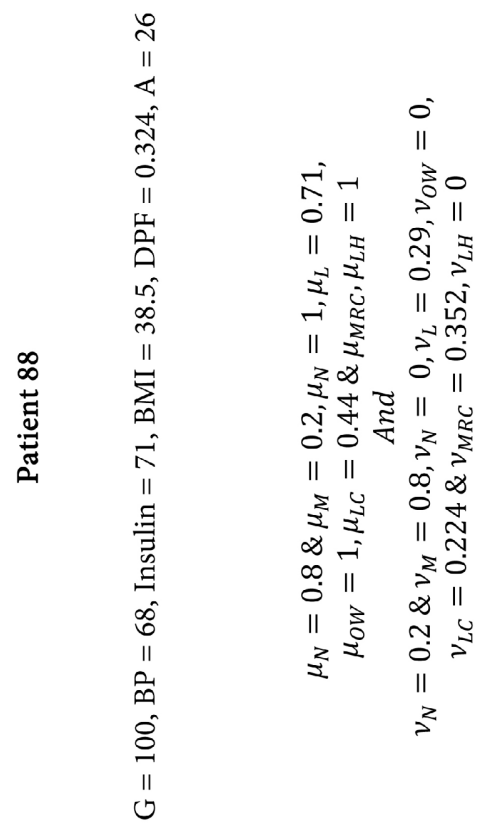

$\varangle \stackrel{\nabla}{\times} \nabla \underset{\times}{\times}$

$x+\frac{2}{x} \times$

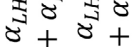

$+4+$

造各造合

$a x a x$

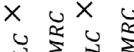

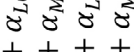

志志

$\sum_{\infty} \infty$

$\times \times \times \times$

今े 今े है

$++++$

$\bar{x} \bar{x} \bar{x}$

चे छे ठै

$++++$

a $\frac{1}{\infty} \frac{0}{\infty}$

$\times \times \times \times$

के के क्ष

$++++$

$\circlearrowleft \circlearrowleft \circlearrowleft$

$x \times \times$

z क व

$++++$

8 व 8

|| || || ||

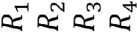

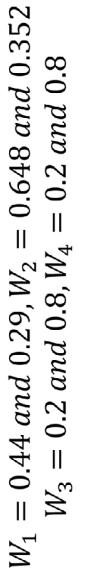

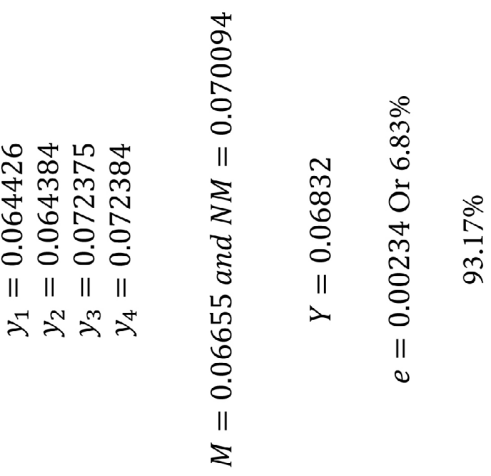

$\varangle \times \times$
$\times \times x$

$x$ I

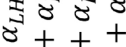

$+\frac{1}{2} \frac{1}{2}$

告方文

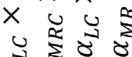

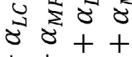

$++\bar{\Sigma}$

$\infty x$

$\begin{array}{lll}x & x & 0 \\ z & 0 & 0 \\ 0 & 0\end{array}$

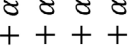

$\bar{x} \bar{x} \bar{x}$

ठै ठै ठे

$++++$

$a 20$

$\times \times \times$

o z क व

$++++$

৫心

$\times \times \times \times$

z z z z

$++++$

岁

उี శ్ర

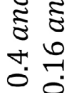

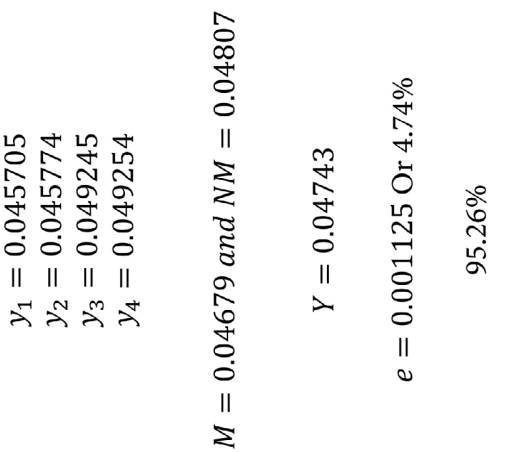

8880

|| || || ||

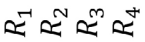




\section{Continued}

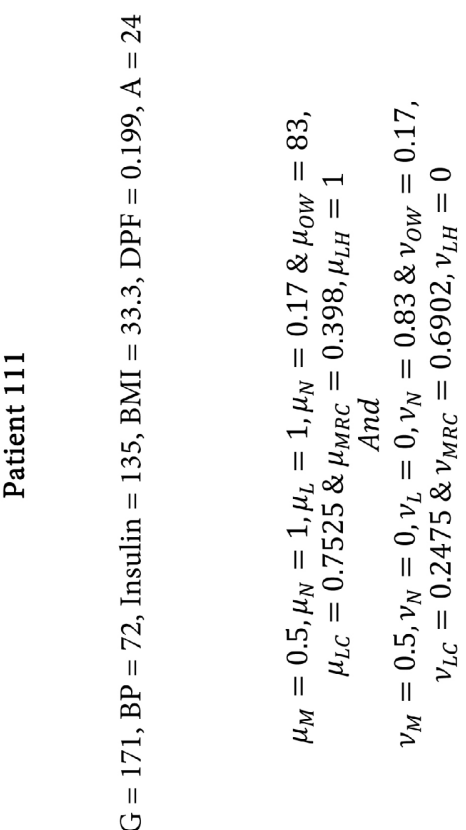

$\nabla \times x \times$

$x \times x=$

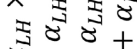

$8++$

$+\frac{1}{2} \frac{1}{a}$

这古公

$x \times x y$

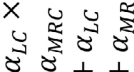

$++=$

住夜

$\infty x \times$

$x \times 3$
$z<0$

$++++$

$\bar{x} \bar{x} \bar{x}$

च छ ठ ठ

$++++$

命 $\frac{2}{0}$

$\times \times \times \times$

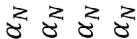

$++++$

$\circlearrowleft \circlearrowleft \circlearrowleft$

$\times \times \times \times$

z $88^{2} e^{2} e^{2}$

$++++$

888

|| || || ||

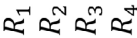

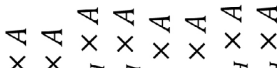

$\times x \times$

इ $\frac{8}{2}$ व ช ++++++

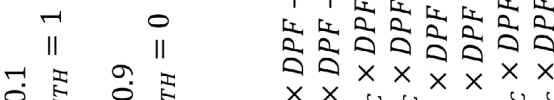

$x \times u v u v u v$

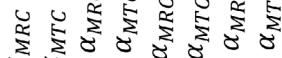

o व ++++++

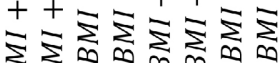

$\sum_{\infty} \sum_{\infty} \infty \sum_{\infty} \infty$

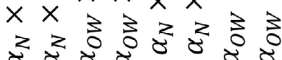

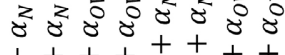

$++++ \pm++$

$\bar{x} \bar{x} \bar{x} \times \times \bar{x} \bar{x}$

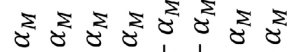

$++++++++$

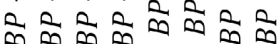

$\times \times \times \times \times \times \times$

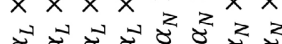

$++++++++$

৫心U心U心心心

$\times \times \times \times \times \times \times \times$

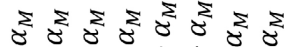

$+++++++$

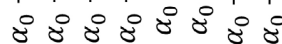

|| || || || || || || ||

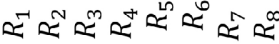

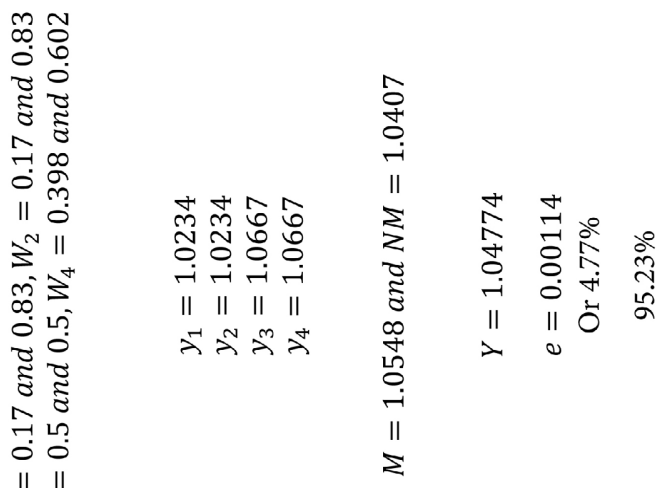

なू̆

₹ี శ్ శ్

○

○ 웅

|| || || ||

$3^{2} 3^{+} 3^{\infty}$

ने

‡

뚱

|| || || ||

웜요

II $\mid$

กิ่ $\lambda^{+} \lambda^{\infty}$

०० के

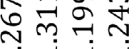

॥ $\|$ \|

$\lambda^{-1} \lambda^{m} \lambda^{n} \lambda^{n}$

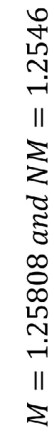

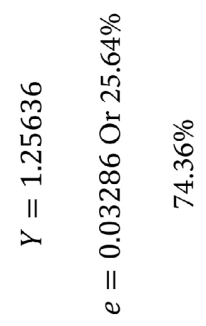




\section{Continued}
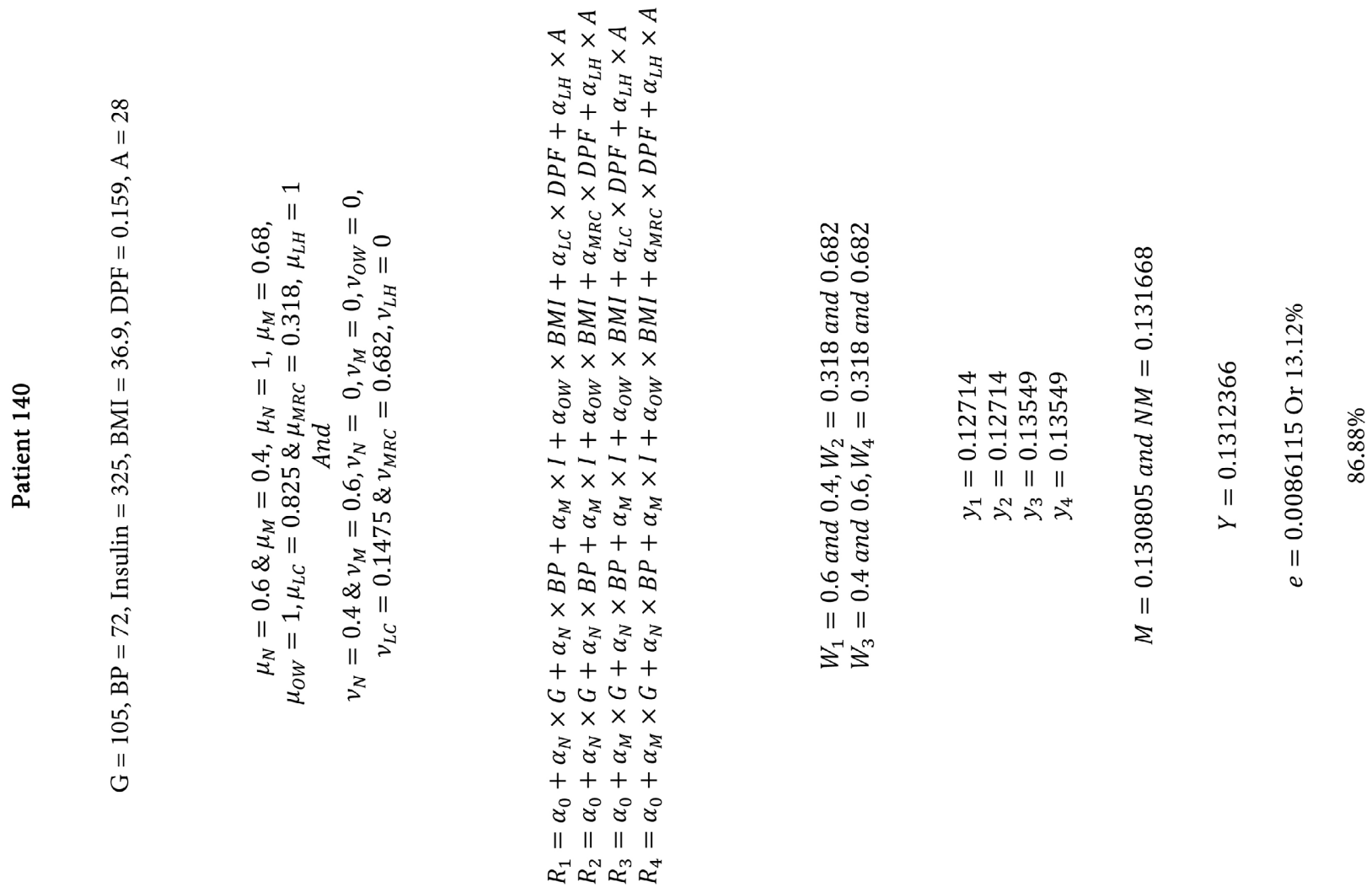

$$
y_{1}=0.0984964 \text { and } y_{2}=0.985037 \text {. }
$$

Layer 6: This is the Implication layer; here we have calculated the value of overall Membership and Non-Membership, as following:

$$
M=\frac{W_{1} y_{1}+W_{2} y_{2}}{W_{1}+W_{2}}=0.0985,
$$

$M$ is membership value:

$$
N M=\frac{W_{1} y_{1}+W_{2} y_{2}}{W_{1}+W_{2}}=0.0985,
$$

$N M$ is non-membership value.

Layer 7: This is the final layer of our structure, which is Output Layer and the output have calculated as:

$$
Y=\frac{M+N M}{2}=0.0985
$$

The error of our structure is shown as:

We have, $Y=0.0985$ and $T=0$ (as given o/p from the given data).

So,

$$
e=\frac{(Y-T)^{2}}{2}=0.00485
$$


Table 3. Comparison of proposed technique's accuracy with the existing [7] [9].

\begin{tabular}{ccc}
\hline Method & $\begin{array}{c}\text { Accuracy } \\
(\%)\end{array}$ & Author(s) \\
\hline Proposed Approach (INFS Structure) & 88.76 & Our Approach \\
FLDDS for Very Young & 87.2 & Vaishali Jain, Supriya Raheja \\
FVM for Diabetes Decision Very Young & 85.03 & Kalpana, M. \\
FES & 81.7 & Kumar, A.V.S. \\
HNFB-1 & 78.26 & Goncalves et al. \\
Logdisc & 77.7 & Statlog \\
IncNet & 77.6 & Norbert Jankowski \\
DIPOL 92 & 77.6 & Statlog \\
\hline
\end{tabular}

\section{Conclusions and Discussions}

The entire work done in this article illustrates the following points:

1) Proposed intuitionistic fuzzy logic-based neuro system shows the diagnostic process of diabetes with the help of membership and non-membership function with some hesitation margins. We have adopted the framework of intuitionistic fuzzy logic-based inference system in the neural network, in which the neural network works as hardware and intuitionistic fuzzy-based inference system works as software.

2) The experimental data of the diabetic patient is collected from PIDD, to check the accuracy of our proposed system and to minimize the complexity of treating diabetes.

3) In this work, a survey has been done on various optimization techniques. We have considered many optimization tools used in existing literature for optimization, the proposed work contains 21 previous studies on optimization in different fields.

4) A comparative study is also given in this work (as revealed in Table 3), the accuracy value of our system has also been calculated as shown in Table 2. The obtained value is $88.76 \%$ which is more optimal than the values obtained in the previously existing techniques. Therefore, the proposed system can help doctors in hospitals to evaluate the risk of diabetes.

5) For the future perspective, the proposed method describes that its performance is increased with the use of any population-based optimization technique and it will provide better results.

6) To decrease the complexity of the system, we have used the MATLAB software to the representation of membership and non-membership values of the input variable. And the further process is handled by using Sugeno's fuzzy inference system based on the intuitionistic fuzzy logic approach.

7) The proposed model has considered the six major input factors (due to the 
effects of these factors on diabetes diseases) for Sugeno's fuzzy inference system in the intuitionistic environment.

\section{Acknowledgements}

The corresponding author is thankful to the Higher Education Department of Uttar Pradesh Government for financial support under the research and development scheme, file number: 47/2021/606/sattar-4-2021-4(56)/2020.

\section{Conflicts of Interest}

The authors declare no conflicts of interest regarding the publication of this paper.

\section{References}

[1] Zadeh, L.A. (1965) Fuzzy Sets. Information and Control, 8, 338-353. https://doi.org/10.1016/S0019-9958(65)90241-X

[2] Kabiraj, A., Nayak, P. and Raha, S. (2019) Solving Intuitionistic Fuzzy Linear Programming Problem. International Journal of Intelligence Science, 9, 44-58. https://doi.org/10.4236/ijis.2019.91003

[3] Kabiraj, A., Nayak, P. and Raha, S. (2019) Solving Intuitionistic Fuzzy Linear Programming Problem-II. International Journal of Intelligence Science, 9, 93-110. https://doi.org/10.4236/ijis.2019.94006

[4] Lee, C.S. and Wang, M.H. (2007) Ontology-Based Intelligent Healthcare Agent and Its Application to Respiratory Waveform Recognition. Expert Systems with Applications, 33, 606-619. https://doi.org/10.1016/j.eswa.2006.06.006

[5] Olej, V. and Hájek, P. (2010) IF-Inference Systems Design for Prediction of Ozone Time Series: The Case of Pardubice Micro-Region. In: Diamantaras, K., Duch, W. and Iliadis, L.S., Eds., Artificial Neural Networks-ICANN 2010. Lecture Notes in Computer Science, Springer, Berlin, 1-11.

https://doi.org/10.1007/978-3-642-15819-3 1

[6] Olej, V. and Hájek, P. (2011) Comparison of Fuzzy Operators for If-Inference Systems of Takagi-Sugeno Type in Ozone Prediction. In: Iliadis, L., Maglogiannis, I. and Papadopoulos, H., Eds., Artificial Intelligence Applications and Innovations. EANN 2011, AIAI 2011. IFIP Advances in Information and Communication Technology, Springer, Berlin, 92-97. https://doi.org/10.1007/978-3-642-23960-1_11

[7] Kalpana, M. and Senthil, A.V.K. (2011) Fuzzy Expert System for Diabetes using Fuzzy Verdict Mechanism. International Journal of Advanced Networking and Applications, 3, 1128-1134.

[8] Habib, S. and Akram, M. (2015) Decision-Making System for Washing Machine Using AIFNN. Mathematical Sciences Letters, 4, 303-311.

[9] Jain, V. and Raheja, S. (2015) Improving the Prediction Rate of Diabetes Using Fuzzy Expert System. International Journal of Information Technology and Computer Science, 10, 84-91. https://doi.org/10.5815/ijitcs.2015.10.10

[10] Ahmadi, H., Gholamzadeh, M., Shahmoradi, L., Nilashi, M. and Rashvand, P. (2018) Diseases Diagnosis Using Fuzzy Logic Methods: A Systematic and Meta-Analysis Review. Computer Methods and Programs in Biomedicine, 161, 145-172. https://doi.org/10.1016/j.cmpb.2018.04.013 
[11] Bressan, G.M., De Azevedo, B.C.F. and De Souza, R.M. (2020) A Fuzzy Approach for Diabetes Mellitus Type 2 Classification. Brazilian Archives of Biology and Technology, 63, e20180742. https://doi.org/10.1590/1678-4324-2020180742

[12] Nauck, D. and Kruse, R. (1995) NEFCLASS-A Neuro-Fuzzy Approach for the Classification of Data. Proceedings of the 1995 ACM Symposium on Applied Computing, Nashville, 26-28 February 1995, 461-465. https://doi.org/10.1145/315891.316068

[13] Musilek, P. and Gupta, M.M. (2000) Fuzzy Neural Networks. In: Sinha, N.K. and Gupta, M.M., Eds., Soft Computing and Intelligent Systems, Academic Press, Cambridge, 161-184. https://doi.org/10.1016/B978-012646490-0/50011-1

[14] Goncalves, L.B., Vellasco, M.M.B.R., Pacheco, M.A.C. and De Souza, F.J. (2006) Inverted Hierarchical Neuro-Fuzzy BSP System: A Novel Neuro-Fuzzy Model for Pattern Classification and Rule Extraction in Databases. IEEE Transactions on Systems, Man, and Cybernetics, Part C: Application and Reviews, 36, 236-248. https://doi.org/10.1109/TSMCC.2004.843220

[15] Jabbar, N.I. and Mehrotra, M. (2008) Application of Fuzzy Neural Network for Image Tumor Description. World Academy of Science, Engineering and Technology, 44, 575-577.

[16] Lee, C.H., Li, C.T. and Chang, F.Y. (2011) A Species-Based Improved Electromagnetism-Like Mechanism Algorithm for TSK-Type Interval Valued Neural Fuzzy System Optimization. Fuzzy Sets and Systems, 171, 22-43. https://doi.org/10.1016/j.fss.2011.02.004

[17] Sremac, S., Zavadskas, E.K., Matić, B., Kopić, M. and Stević, Z. (2019) Neuro-Fuzzy Inference Systems Approach to Decision Support System for Economic Order Quantity. Economic Research-Ekonomska Istraživanja, 32, 1114-1137. https://doi.org/10.1080/1331677X.2019.1613249

[18] Hájek, P. and Olej, V. (2013) Evaluating Sentiment in Annual Reports for Financial Distress Prediction Using Neural Networks and Support Vector Machines. In: Iliadis, L., Papadopoulos, H. and Jayne, C., Eds., Engineering Applications of Neural Networks. EANN 2013. Communications in Computer and Information Science, Springer, Heidelberg, 1-10. https://doi.org/10.1007/978-3-642-41016-1_1

[19] Viharos, Z.J. and Kis, K.B. (2015) Survey on Neuro-Fuzzy Systems and their Applications in Technical Diagnostics and Measurement. Measurement, 67, 126-136. https://doi.org/10.1016/j.measurement.2015.02.001

[20] Geman, O., Chiuchisan, I. and Toderean, R. (2017) Application of Adaptive NeuroFuzzy Inference System for Diabetes Classification and Prediction. 2017 E-Health and Bioengineering Conference (EHB), Sinaia, 22-24 June 2017, 639-642. https://doi.org/10.1109/EHB.2017.7995505

[21] Sremac, S., Tanackov, I, Kopić1, M. and Radović, D. (2018) ANFIS Model for Determining the Economic Order Quantity. Decision Making: Applications in Management and Engineering, 1, 81-92.

[22] Atanassov, K.T. (1986) Intuitionistic Fuzzy Sets. Fuzzy Sets and Systems, 20, 87-96. https://doi.org/10.1016/S0165-0114(86)80034-3

[23] Atanassov, K.T. (1999) Intuitionistic Fuzzy Sets. In: Kacprzyk, J., Ed., Intuitionistic Fuzzy Sets. Studies in Fuzziness and Soft Computing, Physica, Heidelberg, 1-37. https://doi.org/10.1007/978-3-7908-1870-3 1

[24] Sang, B. and Zhang, X. (2020) The Approach to Probabilistic Decision-Theoretic Rough Set in Intuitionistic Fuzzy Information Systems. Intelligent Information Management, 12, 1-26. https://doi.org/10.4236/iim.2020.121001 
[25] Barrenechea, E. (2009) Generalized Atanassov's Intuitionistic Fuzzy Index. Construction Method. IFSA-EUSFLAT, Lisbon, 20-24 July 2009, 478-482.

[26] Hájek, P. and Olej, V. (2012) Adaptive Intuitionistic Fuzzy Inference Systems of TakagiSugeno Type for Regression Problems. In: Iliadis, L., Maglogiannis, I. and Papadopoulos, H., Eds., Artificial Intelligence Applications and Innovations. AIAI 2012. IFIP Advances in Information and Communication Technology, Springer, Berlin, 206-216. https://doi.org/10.1007/978-3-642-33409-2 22

[27] Hájek, P. and Olej, V. (2014) Defuzzification Methods in Intuitionistic Fuzzy Inference Systems of Takagi-Sugeno Type: The Case of Corporate Bankruptcy Prediction. 2014 11 th International Conference on Fuzzy Systems and Knowledge Discovery (FSKD), Xiamen, 19-21 August 2014, 240-244. https://doi.org/10.1109/FSKD.2014.6980838

[28] Hájek, P. and Olej, V. (2015) Intuitionistic Fuzzy Neural Network: The Case of Credit Scoring Using Text Information. In: Iliadis, L. and Jayne, C., Eds., Engineering Applications of Neural Networks. EANN 2015. Communications in Computer and Information Science, Springer, Cham, 337-346. https://doi.org/10.1007/978-3-319-23983-5 31

[29] Zhao, J., Lin, L.Y. and Lin, C.M. (2016) A General Fuzzy Cerebellar Model Neural Network Multidimensional Classifier Using Intuitionistic Fuzzy Sets for Medical Identification. Computational Intelligence and Neuroscience, 2016, Article ID: 8073279. https://doi.org/10.1155/2016/8073279

[30] Eyoh, I., John, R. and De Maere, G. (2018) Interval Type-2 A-Intuitionistic Fuzzy Logic for Regression Problems. IEEE Transactions on Fuzzy Systems, 26, 2396-2408. https://doi.org/10.1109/TFUZZ.2017.2775599

[31] Dutta, P. and Goala, S. (2018) Fuzzy Decision Making in Medical Diagnosis Using an Advanced Distance Measure on Intuitionistic Fuzzy Sets. The Open Cybernetics \& Systemics Journal, 12, 136-149. https://doi.org/10.2174/1874110X01812010136

[32] Samuel, A.E. and Rajakumar, S. (2018) Intuitionistic Fuzzy Sets in Medical Diagnosis. International Journal of Pure and Applied Mathematics, 120, 129-135.

[33] Chao, L., Tan, C., Wang, X. and Zheng, Y. (2019) An Evolving Recurrent Interval Type-2 Intuitionistic Fuzzy Neural Network for Online Learning and Time Series Prediction. Applied Soft Computing, 78, 150-163.

https://doi.org/10.1016/j.asoc.2019.02.032

[34] Lee, S.J. and Ouyang, C.S. (2003) A Neuro-Fuzzy System Modeling with Self-Constructing Rule Generation and Hybrid SVD-Based Learning. IEEE Transactions on Fuzzy Systems, 11, 341-353. https://doi.org/10.1109/TFUZZ.2003.812693

[35] Ouyang, C.-S., Lee, W.-J. and Lee, S.-J. (2005) A TSK-Type Neurofuzzy Network Approach to System Modeling Problems. IEEE Transactions of Systems, Man, and Cybernetics, Part B (Cybernetics), 35, 751-767.

https://doi.org/10.1109/TSMCB.2005.846000

[36] Leng, G. and Mc Ginnity, T.M. (2006) Design for Self-Organizing Fuzzy Neural Networks Based on Genetic Algorithms. IEEE Transactions on Fuzzy Systems, 14, 755-766. https://doi.org/10.1109/TFUZZ.2006.877361

[37] Jadav, K. and Panchal, M. (2012) Optimizing Weights of Artificial Neural Networks using Genetic Algorithms. International Journal of Advanced Research in Computer Science and Electronics Engineering, 1, 47-51.

[38] Bernardo, D., Hagras, H. and Tsang, E. (2013) A Genetic Type-2 Fuzzy Logic Based System for the Generation of Summarized Linguistic Predictive Models for Financial Applications. Soft Computing, 17, 2185-2201.

https://doi.org/10.1007/s00500-013-1102-y 
[39] Jia, W., Zhao, D., Zheng, Y. and Hou, S. (2019) A Novel Optimized GA-Elman Neural Network Algorithm. Neural Computing and Applications, 31, 449-459. https://doi.org/10.1007/s00521-017-3076-7

[40] Wang, J., Gong, B., Liu, H. and Li, S. (2015) Multidisciplinary Approaches to Artificial Swarm Intelligence for Heterogeneous Computing and Cloud Scheduling. Applied Intelligence, 43, 662-675. https://doi.org/10.1007/s10489-015-0676-8

[41] Guzman, J.C., Melin, P. and Prado-Arechiga, G. (2017) Design of an Optimized Fuzzy Classifier for the Diagnosis of Blood Pressure with a New Computational Method for Expert Rule Optimization. Algorithms, 10, Article No. 79. https://doi.org/10.3390/a10030079

[42] Tyagi, K. and Tyagi, K. (2015) A Comparative Analysis of Optimization Techniques. International Journal of Computer Applications, 131, 6-12.

[43] Parouha, R.P. and Verma, P. (2021) State-of-the-Art Reviews of Meta-Heuristic Algorithms with Their Novel Proposal for Unconstrained Optimization and Applications. Archives of Computational Methods in Engineering, 28, 4049-4115.

[44] Fonseca, C.M. and Flemming, P.J. (1993) Genetic Algorithms for Multiobjective: Formulation Discussion and Generalization. Proceedings of the ICGA-93: Fifth International Conference on Genetic Algorithms, San Mateo, 17-22 July 1993, 416-423.

[45] Horn, J., Nafpliotis, N. and Goldberg, D.E. (1994) A Niched Pareto Genetic Algorithm for Multiobjective Optimization. Proceedings of the 1 st IEEE Conference on Evolutionary Computation, IEEE World Congress on Computational Intelligence, Orlando, 27-29 June 1994, 82-87.

[46] Srinivas, N. and Deb, K. (1994) Multiobjective Optimization Using Nondominated Sorting in Genetic Algorithms. Evolutionary Computation, 2, 221-248.

https://doi.org/10.1162/evco.1994.2.3.221

[47] Stützle, T. (1998) Parallelization Strategies for Ant Colony Optimization. In: Eiben A.E., Bäck, T., Schoenauer, M. and Schwefel, H.P., Eds., Parallel Problem Solving from Nature-PPSN V. PPSN 1998. Lecture Notes in Computer Science, Springer, Berlin, 722-731. https://doi.org/10.1007/BFb0056914

[48] Bullnheimer, B., Hartl, R.F. and Strauss, C. (1993) An Improved Ant System Algorithm for the Vehicle Routing Problem. Annals of Operations Research, 89, 319-328. https://doi.org/10.1023/A:1018940026670

[49] Van den Bergh, F. and Engelbrecht, A. (2002) A New Locally Convergent Particle Swarm Optimizer. Proceedings of the IEEE International Conference on Systems, Man and Cybernetics, 7, 6-9.

[50] Yang, C. and Simon, D. (2005) A New Particle Swarm Optimization Technique. Proceedings of 17 th International Conference on Systems Engineering, Las Vegas, 16-18 August 2005, 164-169.

[51] Janson, S. and Middenfort, M. (2006) A Hierarchical Particle Swarm Optimizer and Its Adaptive Variant. IEEE Transactions on Systems, Man, and Cybernetics, Part B (Cybernetics), 35, 1272-1282. https://doi.org/10.1109/TSMCB.2005.850530

[52] Kim, D.H., Abraham, A. and Cho, J.H. (2007) A Hybrid Genetic Algorithm and Bacterial Foraging Approach for Global Optimization. Information Sciences, 177, 39183937. https://doi.org/10.1016/j.ins.2007.04.002

[53] Hu, X.M., Zhung, J. and Li, Y. (2008) Orthogonal Methods Based Ant Colony Search for Solving Continuous Optimization Problems. Journal of Computer Science and Technology, 23, 2-18. https://doi.org/10.1007/s11390-008-9111-5

[54] Yu, B., Yang, Z.-Z. and Yao, B.Z. (2009) An Improved Ant Colony Optimization for 
Vehicle Routing Problem. European Journal of Operational Research, 196, 171-176. https://doi.org/10.1016/j.ejor.2008.02.028

[55] Aljanaby, A., Ku-Mahamud, K.R. and Norwawi, N.M. (2010) An Exploration Technique for The Interacted Multiple Ant Colonies Optimization Framework. Proceedings of the 2010 International Conference on Intelligent Systems, Modelling and Simulation, Liverpool, 27-29 January 2010, 92-95.

https://doi.org/10.1109/ISMS.2010.28

[56] Taspnar, N., Karaboga, D., Yildirim, M. and Akay, B. (2010) Partial Transmit Sequences Based on Artificial Bee Colony Algorithm for Peak-to-Average Power Ratio Reduction in Multicarrier Code Division Multiple Access Systems. IET Communications, 5, 1155-1162. https://doi.org/10.1049/iet-com.2010.0379

[57] El-Abd, M. (2011) Opposition-Based Artificial Bee Colony Algorithm. Proceedings of the 13th Annual Conference on Genetic and Evolutionary Computation, Dublin, 12-16 July 2011, 109-116. https://doi.org/10.1145/2001576.2001592

[58] Sonmez, M. (2011) Artificial Bee Colony Algorithm for Optimization of Truss Structures. Applied Soft Computing, 11, 2406-2418.

https://doi.org/10.1016/j.asoc.2010.09.003

[59] Gupta, D.K., Arora, Y., Singh, U.K. and Gupta, J.P. (2012) Recursive Ant Colony Optimization for Estimation of Parameters of a Function. 2012 1st International Conference on Recent Advances in Information Technology (RAIT), Dhanbad, 15-17 March 2012, 448-454. https://doi.org/10.1109/RAIT.2012.6194620

[60] Rai, D. and Tyagi, K. (2014) Regression Test Case Optimization Using Honey Bee Mating Optimization Algorithm with Fuzzy Rule Base. World Applied Sciences Journal, 31, 654-662.

[61] Tsai, P.W., Khan, M.K., Pan, J.S. and Liao, B.Y. (2014) Interactive Artificial Bee Colony Supported Passive Continuous Authentication System. IEEE Systems Journal, 8, 395-405. https://doi.org/10.1109/JSYST.2012.2208153

[62] Zheng, Y.J. (2015) Water Wave Optimization: A New Nature-Inspired Metaheuristic. Computers \& Operations Research, 55, 1-11. https://doi.org/10.1016/j.cor.2014.10.008

[63] Mirjalili, S. and Lewis, A. (2016) The Whale Optimization Algorithm. Advances in Engineering Software, 95, 51-67. https://doi.org/10.1016/j.advengsoft.2016.01.008

[64] Saremi, S., Mirjalili, S. and Lewis, A. (2017) Grasshopper Optimization Algorithm: Theory and Application. Advances in Engineering Software, 105, 30-47. https://doi.org/10.1016/j.advengsoft.2017.01.004

[65] Yu, H., Tan, Y., Zeng, J., Sun, C. and Jin, Y. (2018) Surrogate-Assisted Hierarchical Particle Swarm Optimization. Information Sciences, 454-455, 59-72. https://doi.org/10.1016/j.ins.2018.04.062

[66] Pierezan, J. and Dos Santos Coelho, L. (2018) Coyote Optimization Algorithm: A New Metaheuristic for Global Optimization Problems. IEEE Congress on Evolutionary Computation, Rio de Janeiro, 8-13 July 2018, 1-8. https://doi.org/10.1109/CEC.2018.8477769

[67] Khajeh, A., Ghasemi, M.R. and Arab, H.G. (2019) Modified Particle Swarm Optimization with Novel Population Initialization. Journal of Information and Optimization Sciences, 40, 1167-1179. https://doi.org/10.1080/02522667.2017.1338605

[68] Shabani, A., Asgarian, B., Gharebaghi, S.A., Salido, M.A. and Giret, A. (2019) A New Optimization Algorithm Based on Search and Rescue Operations. Mathematical Problems in Engineering, 2019, Article ID: 2482543. 
https://doi.org/10.1155/2019/2482543

[69] Hosseini, S.A., Hajipour, A. and Tavakoli, H. (2019) Design and Optimization of A CMOS Power Amplifer Using Innovative Fractional-Order Particle Swarm Optimization. Applied Soft Computing, 85, Article ID: 105831.

https://doi.org/10.1016/j.asoc.2019.105831

[70] Marzbali, A.G. (2020) A Novel Nature-Inspired Meta-Heuristic Algorithm for Optimization: Bear Smell Search Algorithm. Soft Computing, 24, 13003-13035.

[71] Xiong, H., Qiu, B. and Liu, J. (2020) An Improved Multi-Swarm Particle Swarm Optimizer for Optimizing the Electric Field Distribution of Multichannel Transcranial Magnetic Stimulation. Artificial Intelligence in Medicine, 104, Article ID: 101790. https://doi.org/10.1016/j.artmed.2020.101790

[72] Dash, J., Dam, B. and Swain, R. (2020) Design and Implementation of Sharp Edge FIR Filters Using Hybrid Differential Evolution Particle Swarm Optimization. AEUInternational Journal of Electronics and Communications, 114, Article ID: 153019. https://doi.org/10.1016/j.aeue.2019.153019 